\title{
FASEB Journal
}

\section{Gut microbiome catabolites as novel modulators of muscle cell glucose metabolism}

Michael J. Houghton a, Asimina Kerimi ${ }^{\text {a, }}$, Vincent Mouly ${ }^{\text {, }}$, Sarka Tumova ${ }^{\text {a }}$, Gary

Williamson ${ }^{\mathrm{a}, *}$

${ }^{a}$ School of Food Science and Nutrition, Faculty of Maths and Physical Sciences, University of Leeds, Leeds, LS2 9JT, UK

${ }^{b}$ Sorbonne Université, INSERM, Institute of Myology, Centre of Research in Myology, UMRS 974, F-75013, Paris, France

*Correspondence: e-mail g.williamson@leeds.ac.uk; Phone +44 113343 8380; Fax +44 113 3432982

Short, running title: Microbiome catabolites modulate muscle metabolism

Keywords: phenolic; flavonoid; muscle; gut microbiota; glucose; insulin 


\section{Abbreviations}

2-DG - 2-[ $\left[{ }^{14} \mathrm{C}(\mathrm{U})\right]$-deoxy-D-glucose; Akt - protein kinase B; p-Akt - phosphorylated Akt; AMPK $-5^{\prime}$ adenosine monophosphate-activated protein kinase; BCA - bicinchoninic acid; $\mathrm{CS}$ - catechol-O-sulfate; DCF - 2', 7'-dichlorofluorescin; DCFH-DA - 2',7'dichlorofluorescin diacetate; DHFA - dihydroferulic acid; DHFA-4S - dihydroferulic acid 4sulfate; FA4S - ferulic acid 4-O-sulfate; GLUT - glucose transporter; Glc/Ins glucose/insulin; GYS1 - glycogen synthase; INSR - insulin receptor; IRS - insulin receptor substrate; IVA - isovanillic acid; IVAS - isovanillic acid 3-O-sulfate; $\mathrm{K} 3 \mathrm{G}$ - kaempferol 3$O$ - $\beta$-D-glucuronide; MCS - 4-methylcatechol- $O$-sulfate; MGS - 4-methylgallic-3- $O$-sulfate; OAT - organic anion transporter; PCA - protocatechuic acid; PI3K - phosphatidylinositol4,5-bisphosphate 3-kinase; PGS - pyrogallol-O-sulfate; PKC - protein kinase C; Q3G quercetin 3-O- $\beta$-D-glucuronide; $\mathrm{Q} 3 \mathrm{~S}$ - quercetin 3'-O-sulfate; R3G - trans-resveratrol 3-Oglucuronide; R4G - trans-resveratrol 4'-O- $\beta$-D-glucuronide; R3S - trans-resveratrol 3sulfate; SLC22A $(6,7,8,11)$ - solute carrier family 22 member $(6,7,8,11)$; VAS - vanillic acid-4-O-sulfate. 


\begin{abstract}
The gut microbiome supplies essential metabolites such as short chain fatty acids to skeletal muscle mitochondria, and the composition and activity of the microbiota is in turn affected by muscle fitness. To further our understanding of the complex interactions between the gut microbiome and muscle, we examined the effect of microbiota-derived phenolic metabolites on the ability of human muscle cells to take up and metabolize glucose. As a model, we used the differentiated human skeletal muscle myoblast line, LHCN-M2, which expresses typical muscle phenotypic markers. We initially tested a selected panel of parent phenolic compounds and microbial metabolites, and their respective phenolic conjugates, as found in blood. Several of the tested compounds increased glucose uptake and metabolism, notably in high glucose and insulin-treated myotubes. One of the most effective was isovanillic acid 3$O$-sulfate (IVAS), a metabolite from the microbiome found in the blood, primarily derived from consumed cyanidin 3-O-glucoside, a major compound in berry fruits. IVAS stimulated a dose-dependent increase in glucose transport through a GLUT4- and PI3K-dependent mechanism. IVAS also upregulated GLUT1, GLUT4 and PI3K p85 $\alpha$ protein, and increased phosphorylation of Akt. The stimulation of glucose uptake and metabolism by a unique microbiome metabolite provides a novel link between the diet, gut microbiota and skeletal muscle energy source utilization.
\end{abstract}




\section{Introduction}

Skeletal muscle is the primary site of postprandial glucose disposal (1), where the glucose transporter GLUT4 is activated in response to insulin by translocation from internal vesicles to the plasma membrane $(2,3)$. In diabetic and pre-diabetic insulin-resistant tissues, insulin driven GLUT4 translocation is compromised (4). Therapeutic strategies against insulin resistance, including exercise and diet-related interventions, aim at lower postprandial glycemia at least partly by restoring skeletal muscle glucose uptake and enhancing metabolism $(5,6)$. One of the most commonly studied classes of gut microbial metabolites are short chain fatty acids (SCFA), which affect host metabolism by acting on mitochondria in skeletal muscle cells, and indeed an important SCFA, butyrate, is correlated with fitness levels (7). Further, the gut microbiome has a profound influence on inflammatory states (8) and on metabolism during exercise (9); as such trained athletes have a distinctly different microbiome compared to sedentary individuals (10). Endurance exercise requires enhanced energy-generating processes, with increased mitochondrial biogenesis leading to elevated ROS. The gut microbiota regulate mitochondrial biogenesis through modulation of PGC-1 $\alpha$, SIRT1 and AMPK as suggested, for example, by studies where germ-free mice had elevated AMPK and PGC-1 $\alpha$ expression in skeletal muscle (11). The gut microbiota-produced metabolites such as SCFA and secondary bile acids can also contribute to host energy production. In return, mitochondria regulate some aspects of the gut microbiota by modulating intestinal barrier function and mucosal immune responses (12).

One of the ways in which the microbiome communicates with the body is through production of distinctive biologically active metabolites. Some of these, such as butyrate, have been well studied (13), and multiple actions have been observed in muscle and other tissue $(7,14)$. Butyrate is mainly derived from "prebiotic" dietary fiber which is undigested in the small intestine, enters the colon and acts as a fermentation substrate for the microbiota $(15,16)$. Dietary phenolics are another class of common prebiotic-type molecules, and this group includes precursor molecules found in unbound form as well as those covalently attached to some dietary fibers such as cereal brans (17). After microbial action, many potentially bioactive compounds are released and absorbed in the colon from multiple substrates, including phenolics $(18,19)$, but the action of these compounds on the body is only beginning to be explored $(20,21)$. The situation is complicated by the range of possible 
modifications that can occur in vivo such as glucuronidation, sulfation, glutathionylation and methylation $(22,23)$; however, these modified compounds can be present in the blood at high concentrations and remain for long periods of time, increasing the exposure time to body tissues and organs (19).

Since rodent muscle cells show substantial differences to human cells, including (a) the myogenic programming that regulates differentiation (24) and (b) glucose transport kinetics in response to insulin and GLUT4 expression (25), in the work presented here we specifically chose to use differentiated human muscle cells to understand the mechanisms linking the gut microbiome to glucose uptake. In addition, as immortalized human muscle cell lines rarely retain their muscle phenotype, as part of this work we further characterized and exploited the LHCN-M2 immortalized human skeletal muscle cell line (26). We then exposed these cells to metabolites of microbial catabolism of commonly-consumed phenolics and examined their effect on glucose uptake and metabolism, especially relevant to post-prandial physiology, insulin responses and type 2 diabetes. 


\section{Materials and Methods}

\section{Chemical compounds and reagents}

All reagents were purchased from Sigma-Aldrich (Gillingham, UK) unless otherwise stated. High purity (18.2 $\mathrm{M} \Omega \mathrm{cm}^{-1}$ ) water supplied by a MilliQ system (Merck Millipore UK, Watford, UK) was used throughout. Ferulic acid 4-O-sulfate (FA4S) and dihydroferulic acid 4-O-sulfate (DHFA-4S) were synthesized according to (27). Dihydroferulic acid (DHFA) was purchased from Alfa Aesar (Thermo Fisher Scientific, Warrington, UK). Quercetin 3'-Osulfate (Q3S) was synthesized as previously described (28). Quercetin 3-O- $\beta$-D-glucuronide $(\mathrm{Q} 3 \mathrm{G})$, kaempferol 3-O- $\beta$-D-glucuronide (K3G) and isovanillic acid (IVA) were from SigmaAldrich. Trans-resveratrol 4'-O- $\beta$-D-glucuronide (R4G), trans-resveratrol 3-O-sulfate (R3S) and trans-resveratrol 3-O- $\beta$-D-glucuronide (R3G) were from Bertin Pharma (Montigny-leBretonneux, France). Catechol- $O$-sulfate (CS), 4-methylcatechol- $O$-sulfate (MCS), pyrogallol- $O$-sulfate (PGS), 4-methylgallic acid 3-O-sulfate (MGS), vanillic acid 4-O-sulfate (VAS) and isovanillic acid 3-O-sulfate (IVAS) were chemically/enzymically synthesized and characterized as described previously $(29,30) .2-\left[1-{ }^{14} \mathrm{C}(\mathrm{U})\right]$-deoxy-D-glucose and D$\left[{ }^{14} \mathrm{C}(\mathrm{U})\right]$-glucose were both from PerkinElmer (Beaconsfield, UK).

\section{Cell culture and differentiation of LHCN-M2 myoblasts}

LHCN-M2 myoblasts are derived from a selected myogenic clone of an immortalized population of human satellite cells, originally from the pectoralis major muscle of a 41-year old Caucasian heart-transplant donor (26). Myoblasts were maintained in Dulbecco's Modified Eagle Medium (DMEM) (Gibco, Life Technologies, Thermo Fisher Scientific, UK) supplemented with $5.5 \mathrm{mM}$ glucose, $10 \% \mathrm{v} / \mathrm{v}$ heat-inactivated fetal bovine serum, $10 \% \mathrm{v} / \mathrm{v}$ heat-inactivated newborn calf serum (Gibco), animal-free recombinant human epidermal growth factor ( $5 \mu \mathrm{g}$; PeproTech, London, UK), animal-origin free recombinant human basic fibroblast growth factor $(0.5 \mu \mathrm{g}$; Gibco) and dexamethasone $(200 \mu \mathrm{g})$, and sterile-filtered. Cells were passaged before reaching confluence, at least every $4 \mathrm{~d}$. For experiments, once myoblasts reached $\sim 80-90 \%$ confluence they were differentiated to myotubes for $96 \mathrm{~h}$ following replacement of growth medium with differentiation medium (DMEM supplemented with 5.5 or $25 \mathrm{mM}$ glucose, 10 or $50 \mathrm{nM}$ recombinant human insulin (Sigma- 
Aldrich) and 2\% horse serum (Gibco)). Differentiation medium was changed every day. The progress of differentiation was monitored daily by observing the formation of elongated and multinucleated myotubes using an inverted microscope (Leica MD IL LED) and characterization of myotube formation is shown in the Results section (Fig. 1). Cells were kept in a humidified atmosphere of $5 \% \mathrm{CO}_{2} / 95 \%$ air at $37^{\circ} \mathrm{C}$ and used for experiments over six passages. Sub-culturing was done in 75 or $175 \mathrm{~cm}^{2}$ flasks and for experiments, cells were seeded on 6-well plates (Corning, Appleton Woods, UK), 100 or $150 \mathrm{~mm}$ dishes (Greiner CELLSTAR, Stonehouse, UK) at a density equivalent to $\sim 1.8 \times 10^{4}$ cells $\mathrm{cm}^{-2}$.

\section{Measurement of LHCN-M2 myoblast viability}

Viability of LHCN-M2 myoblasts was assessed using the Trypan Blue exclusion assay (31). Cells were lifted with $0.05 \%$ trypsin-EDTA, resuspended in growth medium, an aliquot was mixed 1:1 (v/v) with $0.4 \%$ Trypan Blue-PBS and the cells were counted on the hemocytometer.

\section{Treatment of LHCN-M2 myotubes for protein analysis}

Stocks of compounds (Fig. 2) were dissolved in DMSO (at a final maximum $0.2 \% \mathrm{v} / \mathrm{v}$ concentration) and diluted in cell culture medium. LHCN-M2 myotubes, differentiated for 96 $\mathrm{h}$ in $5.5 \mathrm{mM}$ glucose and $10 \mathrm{nM}$ insulin, or in $25 \mathrm{mM}$ glucose and $50 \mathrm{nM}$ insulin as described above, were starved of glucose, insulin and serum in the presence of test compound(s) or appropriate DMSO control for $4 \mathrm{~h}$ before experiments. After washing twice with PBS, LHCN-M2 myotubes were scraped into PBS supplemented with $1 \%(\mathrm{v} / \mathrm{v})$ protease and phosphatase inhibitors cocktail (Roche, Sigma-Aldrich, UK) and centrifuged at $500 \mathrm{~g}, 4^{\circ} \mathrm{C}$ for $5 \mathrm{~min}$. PBS was aspirated and the pellet was snap-frozen in a dry ice/ethanol bath. Samples were stored at $-80^{\circ} \mathrm{C}$ until analysis. Cell pellets were lysed in Bicine/CHAPS lysis buffer (ProteinSimple, Bio-Techne, San Jose, CA, USA) and the total protein was measured by the bicinchoninic acid (BCA) method (32). Whole cell lysates of HepG2, Caco-2/TC7 and HUVEC cells prepared in the same way were used as negative controls for the GLUT4 analysis and human skeletal muscle whole tissue lysate (Novus, Bio-Techne) diluted in Bicine/CHAPS served as a positive control. 


\section{Protein analysis by automated Western blotting in nanocapillaries (ProteinSimple)}

Whole cell lysates were analyzed for protein by automated western blotting, "WES" (ProteinSimple, Bio-Techne) according to the manufacturer's guidelines. Samples were denatured at $37^{\circ} \mathrm{C}$ for $20 \mathrm{~min}$ in Bicine/CHAPS. Troponin $\mathrm{T}$ (mouse anti-troponin $\mathrm{T}$ (cardiac), CT3, Developmental Studies Hybridoma Bank, University of Iowa, Iowa City, IA, USA) was used as a marker of differentiated muscle (33), PI3K subunit $\mathrm{p} 85 \alpha$ as a marker of the insulin signaling pathway proteins (34) (mouse anti-PI3K (subunit p85 $\alpha$ ), MAB2998, Novus, Bio-Techne), and rabbit anti-Akt (\#9272, Cell Signaling Technology, Beverley, MA, USA) and rabbit anti-phospho-Akt ( $\operatorname{Ser}^{473}$ ) (Cell Signaling Technology) were used to determine the p-Akt/Akt ratio, a marker of insulin signaling pathway activation (35). Mouse anti-GLUT4 (1F8) was also from Cell Signaling Technology and rabbit anti-GLUT1 (ab115730) was from Abcam (Cambridge, UK). Antibodies were duplexed with mouse anti$\alpha$-actinin 1 (MAB8279, Novus, Bio-Techne) or rabbit anti- - $\alpha$-actinin ((D6F6) XP \#6487, Cell Signaling Technology) as loading controls. Mouse or rabbit secondary antibodies were used neat as supplied (ProteinSimple). Samples were loaded onto the "WES" system at a final total protein concentration of $0.4 \mathrm{mg} / \mathrm{ml}$ for troponin T/ $\alpha$-actinin 1 and for PI3K $\mathrm{p} 85 \alpha / \alpha$ actinin $1,0.5 \mathrm{mg} / \mathrm{ml}$ for GLUT4/ $\alpha$-actinin 1 and $0.1 \mathrm{mg} / \mathrm{ml}$ for GLUT1/ $\alpha$-actinin and for (p)Akt/ $\alpha$-actinin. See supplementary figures (S1-S5) for full setup and validation of antibodies.

\section{Uptake of 2-[1- $\left.{ }^{14} \mathrm{C}(\mathrm{U})\right]$-deoxy-D-glucose and $D-\left[{ }^{14} \mathrm{C}(\mathrm{U})\right]$-glucose}

Following the $4 \mathrm{~h}$ incubation with test compounds or control, LHCN-M2 myotubes were further incubated with various insulin concentrations, test compounds or DMSO in $0.55 \mathrm{mM}$ deoxy-D-glucose $\left(0.15 \mu \mathrm{Ci} / \mathrm{ml} 2-\left[1-{ }^{14} \mathrm{C}(\mathrm{U})\right]\right.$-deoxy-D-glucose $)$ in DMEM for $30 \mathrm{~min}$, or in $0.55 \mathrm{mM}$ glucose $\left(0.2 \mu \mathrm{Ci} / \mathrm{ml} \mathrm{D}-\left[{ }^{14} \mathrm{C}(\mathrm{U})\right]\right.$-glucose $)$ in DMEM for $4 \mathrm{~h}$. Cells were then washed twice with medium (without glucose and serum) and lysed in $1 \mathrm{M} \mathrm{NaOH}$ for radioactivity measurements by liquid scintillation counting on a Tri-Carb 1900 TR Liquid Scintillation Analyzer (Canberra Packard, Harwell, Oxford, UK). Counts were corrected for total protein, measured with the Bradford assay (Thermo Fisher Scientific) $(36,37)$.

\section{2', $7^{\prime}$-dichlorofluorescin diacetate (DCFH-DA) assay}


The DCFH-DA assay was conducted as described previously (38). Briefly, cells were washed with PBS, incubated with $10 \mu \mathrm{M}$ DCFH-DA in PBS at $37^{\circ} \mathrm{C}$ for $20 \mathrm{~min}$ in darkness, washed again and fluorescence measured on a PheraSTAR FS (BMG LabTech) plate reader (Ex/Em $=485 / 530 \mathrm{~nm})$. Cells were then scraped and lysed into CellLytic supplemented with $1 \%(\mathrm{v} / \mathrm{v})$ protease inhibitor cocktail and total protein was measured using the Bradford assay. Fluorescence was corrected for protein.

\section{Statistical analyses}

Data are expressed as mean \pm standard error of the mean. The significance of differences between groups of treatments was analyzed by one-way ANOVA and post hoc Tukey's (for unequal sample sizes), Dunnett's (comparing multiple treatments to a single control) or twotailed $t$-tests accordingly, with variance checks using Levene's test, and with Bonferroni correction where multiple treatments were compared, using SPSS 24. A $p$ value $<0.05$ was considered as statistically significant. 


\section{Results}

\section{Characterization of differentiated human skeletal muscle LHCN-M2 myotubes}

LHCN-M2 myoblasts gradually differentiated into myotubes, as identified by multinucleated fibers formed by fused cells (Fig. 1A). During the differentiation process $\alpha$-actinin 1 levels were stable while troponin $\mathrm{T}$ increased by $\sim 50 \%$ every $24 \mathrm{~h}$ (Fig. 1B). Insulin dosedependently increased 2-[1- $\left.{ }^{14} \mathrm{C}(\mathrm{U})\right]$-deoxy-D-glucose (Fig. 1C) and D- $\left[{ }^{14} \mathrm{C}(\mathrm{U})\right]$-glucose uptake (Fig. 1D). In contrast, in undifferentiated myoblasts, insulin did not stimulate 2-[1$\left.{ }^{14} \mathrm{C}(\mathrm{U})\right]$-deoxy-D-glucose uptake (Fig. 1E). Differentiation in high glucose, compared to normal glucose, increased DCF fluorescence as a marker of reactive oxygen species (ROS), which was further amplified by insulin (Fig. 1F). Troponin T and GLUT4 protein levels increased with differentiation but were unaffected by glucose and insulin concentration used (Fig. 1G and H). In comparison, GLUT1 protein expression was decreased by approximately $25 \%$ by the end of the differentiation period in the cells in $5.5 \mathrm{mM}$ glucose and $10 \mathrm{nM}$ insulin, and by a further $10 \%$ in the cells in higher glucose and insulin (Fig. 1I). Subsequent experiments were performed on cells differentiated for $96 \mathrm{~h}$ in either $5.5 \mathrm{mM}$ glucose with 10 $\mathrm{nM}$ insulin, or in $25 \mathrm{mM}$ glucose with $50 \mathrm{nM}$ insulin, referred to hereafter as "normal" or "high" glucose/insulin (Glc/Ins) respectively. In the absence of insulin, 5.5 and $25 \mathrm{mM}$ glucose are referred to as "normal" and "high" glucose respectively.

\section{Effect of metabolite mixtures on $2-\left[1-{ }^{14} \mathrm{C}(\mathrm{U})\right]$-deoxy-D-glucose uptake in differentiated human skeletal muscle LHCN-M2 myotubes}

Insulin stimulated the uptake of $2-\left[1-{ }^{14} \mathrm{C}(\mathrm{U})\right]$-deoxy-D-glucose, a non-metabolizable form of glucose used as a measure of intracellular glucose transport only (39), in LHCN-M2 myotubes (Fig. 3). In cells differentiated in normal Glc/Ins, and in the absence of insulin in the assay, a combination of ferulic acid derivatives (FA4S, DHFA-4S and DHFA, Fig. 2A) or of flavonol conjugates (Q3S, Q3G and K3G, Fig. 2B) exhibited no effect (Fig. 3A and B), whereas the resveratrol conjugates combination (R4G, R3S and R3G, Fig. 2C) and the phenolic conjugates mixture (CS, MCS, PS, MGS, VAS and IVAS, Fig. 2D) significantly stimulated 2-[1- $\left.{ }^{14} \mathrm{C}(\mathrm{U})\right]$-deoxy-D-glucose uptake similar to insulin (Fig. $3 \mathrm{C}$ and D). In the presence of insulin the effective combinations did not produce further changes, while the 
ferulic acid derivatives even led to attenuation of insulin activity (Fig. 3A-D). For the cells differentiated in high Glc/Ins, and without insulin in the assay, all of the treatments except for the flavonol conjugates stimulated (deoxy)glucose uptake, displaying an insulin-like effect. Notably, the effect of insulin was enhanced in the presence of the phenolic conjugates (Fig 3D). Based on these data, the phenolic conjugates exerted a robust insulin-like effect on (deoxy)glucose transport into LHCN-M2 myotubes differentiated both in the presence of normal and high glucose/insulin.

\section{Effect of metabolite mixtures on D-[ $\left.{ }^{14} \mathrm{C}(\mathrm{U})\right]$-glucose uptake in differentiated human skeletal muscle LHCN-M2 myotubes}

The assays using D- $\left[{ }^{14} \mathrm{C}(\mathrm{U})\right]$-glucose indicate the rate of glucose uptake and subsequent metabolism over the longer time period $(4 \mathrm{~h})$. Performing these assays alongside the acute assays with $2-\left[1-{ }^{14} \mathrm{C}(\mathrm{U})\right]$-deoxy-D-glucose elucidates whether the subsequent metabolism is likely anabolic or catabolic. For example, an effect whereby acute uptake with 2-[1- $\left.{ }^{14} \mathrm{C}(\mathrm{U})\right]-$ deoxy-D-glucose was increased, but intracellular D- $\left[{ }^{14} \mathrm{C}(\mathrm{U})\right]$-glucose after $4 \mathrm{~h}$ was decreased, would indicate that glucose transport, catabolism and expulsion from the cells was increased. However, increased transport and increased intracellular ${ }^{14} \mathrm{C}$-label after $4 \mathrm{~h}$ would indicate anabolism, with glucose being converted to glycogen for example (4). In cells differentiated under normal Glc/Ins concentrations, none of the metabolite mixtures affected D- $\left[{ }^{14} \mathrm{C}(\mathrm{U})\right]-$ glucose uptake and metabolism significantly, except for the resveratrol conjugates which slightly suppressed it (Fig. 3E to H). Insulin-stimulated uptake of D-[ $\left[{ }^{14} \mathrm{C}(\mathrm{U})\right]$-glucose in LHCN-M2 myotubes was not changed by any of the tested combinations in normal Glc/Ins cells (Fig. 3).However, for the high Glc/Ins-differentiated cells, where intracellular ROS levels are higher according to the DCF assay, the results were somewhat different. In the absence of insulin (in the assay), ferulic acid derivatives and resveratrol conjugates decreased $\mathrm{D}-\left[{ }^{14} \mathrm{C}(\mathrm{U})\right]$-glucose uptake, indicating an opposing effect to insulin and increased catabolism, while the flavonol and phenolic conjugates had no obvious effect (Fig. 3E and G). In the presence of insulin, the flavonol conjugates and the resveratrol conjugates attenuated D$\left[{ }^{14} \mathrm{C}(\mathrm{U})\right]$-glucose uptake, indicating a blunting of the insulin effect, while ferulic acid derivatives and phenolic conjugates did not influence insulin activity. 


\section{Effect of individual metabolites on $2-\left[1-{ }^{14} \mathrm{C}(\mathrm{U})\right]$-deoxy-D-glucose and $\mathrm{D}-\left[{ }^{14} \mathrm{C}(\mathrm{U})\right]$-glucose uptake in differentiated human skeletal muscle LHCN-M2 myotubes}

As the most notable effects of the metabolite mixtures were observed under high glucose, and consequently highest metabolic and oxidative stress, we tested individual metabolites predominantly under these conditions. Across all compounds, increases in $2-\left[1-{ }^{14} \mathrm{C}(\mathrm{U})\right]-$ deoxy-D-glucose uptake were primarily due to sulfated conjugates: FA4S and DHFA-4S increased uptake by $\sim 15 \%$ ( $p<0.05$ ) (Fig. 4A), R3S by $\sim 25 \%(p<0.001)$ (Fig. 4C) and IVAS by $\sim 40 \%$ in addition to the insulin-stimulated increase $(p<0.001)$ (Fig. 4D). The only glucuronide conjugate to exert an effect was $\mathrm{R} 4 \mathrm{G}$, with a $\sim 25 \%$ increase $(p<0.01)$ (Fig. 4C). Individual flavonol conjugates were inactive (Fig. 4B). For uptake of D- $\left[{ }^{14} \mathrm{C}(\mathrm{U})\right]$-glucose into LCCN-M2 myotubes, DHFA-4S and R4G decreased intracellular ${ }^{14} \mathrm{C}$-label, both independently of insulin (Fig. 4E, 4G). Q3G and K3G also lowered intracellular ${ }^{14} \mathrm{C}$-label in some conditions (Fig. 4F). Since IVAS was the most active of the phenolic conjugates on 2$\left[1-{ }^{14} \mathrm{C}(\mathrm{U})\right]$-deoxy-D-glucose uptake (Fig. 4D), this metabolite was further examined. IVAS lowered intracellular ${ }^{14} \mathrm{C}$-label derived from D- $\left[{ }^{14} \mathrm{C}(\mathrm{U})\right]$-glucose in the absence of insulin in myotubes differentiated in both normal and high Glc/Ins, however this was not evident in the presence of insulin (Fig. 4H).

\section{Mechanism of action of IVAS on LHCN-M2 myotubes}

IVAS dose-dependently increased 2-[1- $\left.{ }^{14} \mathrm{C}(\mathrm{U})\right]$-deoxy-D-glucose uptake (Fig. 5A, 5B), comparable to the action of insulin (Fig. 1C, 1D). Quantitatively, 2-[1- $\left.{ }^{14} \mathrm{C}(\mathrm{U})\right]$-deoxy-Dglucose uptake was higher in myotubes differentiated in normal Glc/Ins, but the high Glc/Ins conditions made the cells more responsive to IVAS when considered as a fold change (Fig. 5B). IVAS-stimulated uptake of $2-\left[1-{ }^{14} \mathrm{C}(\mathrm{U})\right]$-deoxy-D-glucose was observed both in the presence and absence of acute insulin, and also in myotubes differentiated under normal or high Glc/Ins (Fig. 5C). At a high concentration of IVAS $(>10 \mu \mathrm{M})$, where its effect reached a plateau, isovanillic acid (IVA) was equally effective (Fig. 5C) and thus the effects on LHCN-M2 not dependent on the sulfate group of the metabolite.

The PI3K inhibitor wortmannin, and the GLUT4 inhibitor indinavir, both prevented insulinstimulated 2-[1- $\left.{ }^{14} \mathrm{C}(\mathrm{U})\right]$-deoxy-D-glucose uptake, but neither had an effect on basal uptake, 
as expected. The effect of IVAS was also abolished by the same inhibitors (Fig. 5D). When treated with IVAS for only $30 \mathrm{~min}$, i.e. bypassing the $4 \mathrm{~h}$ pre-treatment, $2-\left[1-{ }^{14} \mathrm{C}(\mathrm{U})\right]$-deoxyD-glucose uptake was still increased in LHCN-M2, although less pronounced than with the longer-term treatment, and the inhibitors also prevented the effect of this shorter term incubation (Fig. 5E).

Expression of Troponin T protein, a differentiation marker, was unaffected by treatment with IVAS in both normal and high Glc/Ins (Fig. 6A) while GLUT4 expression was substantially increased in both normal and high Glc/Ins by $\sim 60 \%(p<0.001)$ (Fig. 6B). IVAS treatment restored protein levels of GLUT1, suppressed by $20 \%$ under high Glc/Ins conditions, but did not further increase GLUT1 protein expression (Fig. 6C). PI3K p $85 \alpha$ protein was increased by IVAS in both normal and high Glc/Ins conditions, with a more pronounced effect in the latter (Fig. 6D). Akt phosphorylation was increased by insulin and inhibited by wortmannin as expected, and was increased by IVAS in both normal and high Glc/Ins conditions (Fig. $6 \mathrm{E})$. The combination of IVAS and insulin appears to be synergistic for increasing Akt phosphorylation (Fig. 6E). 


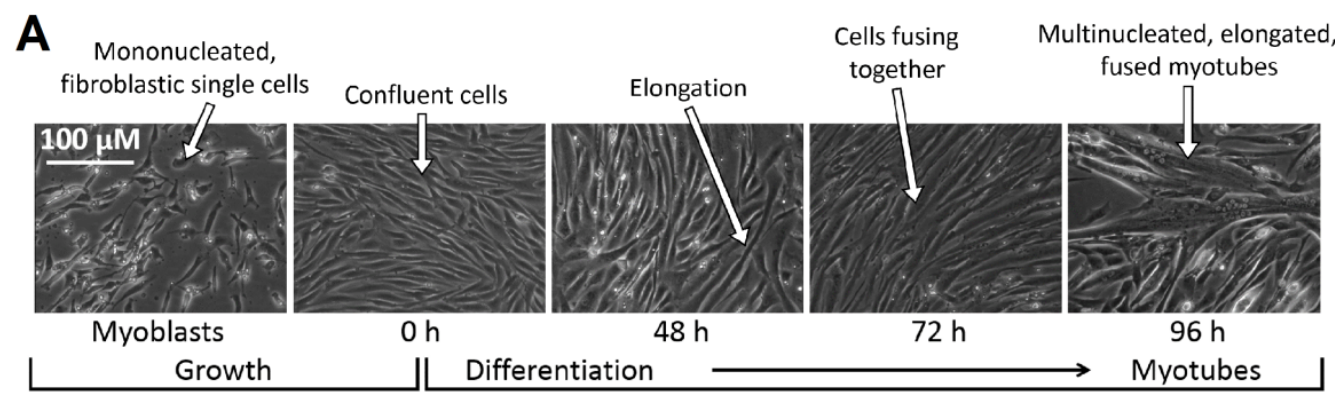

\section{B}

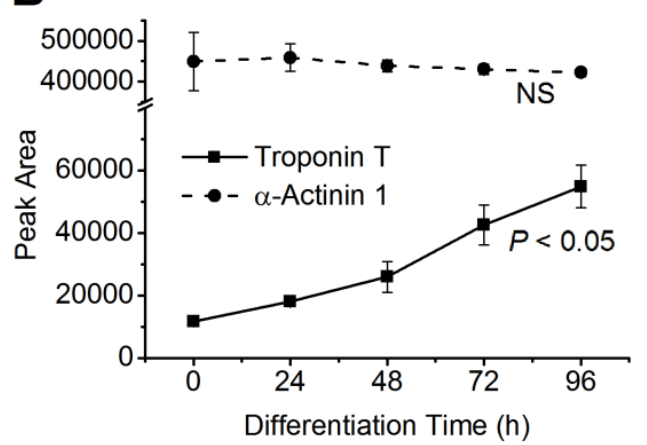

D

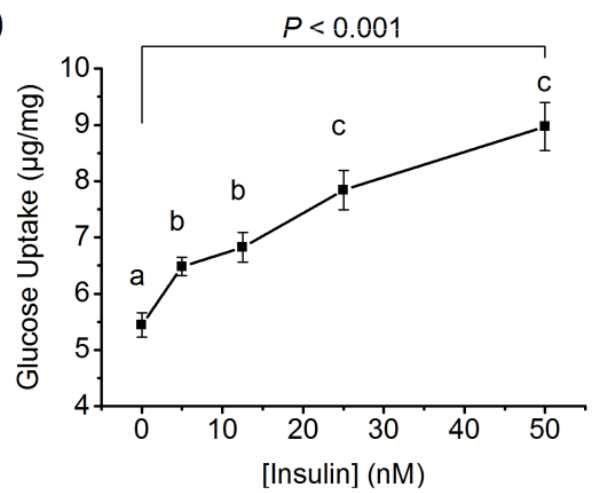

F

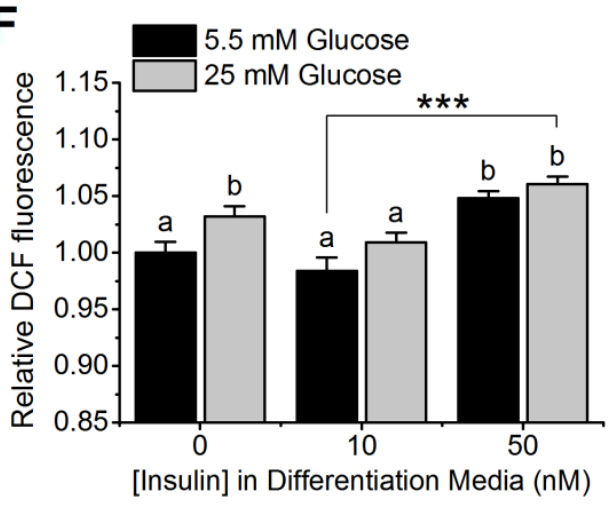

H

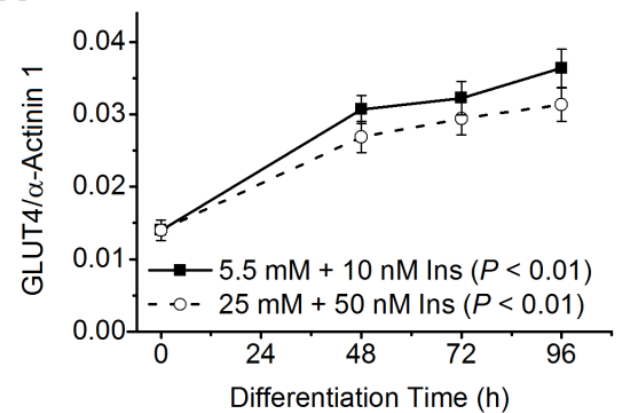

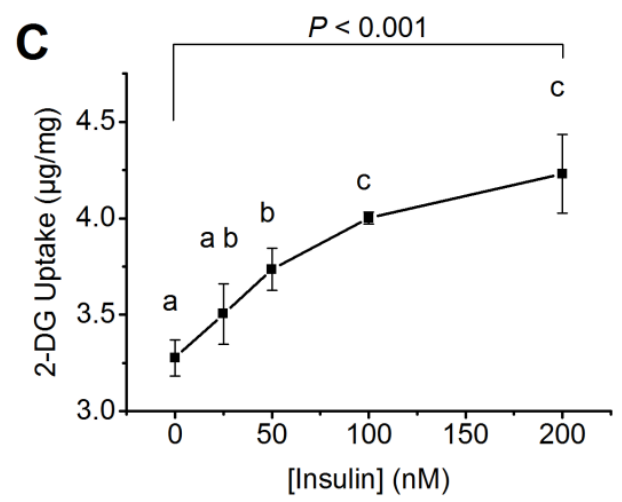

E
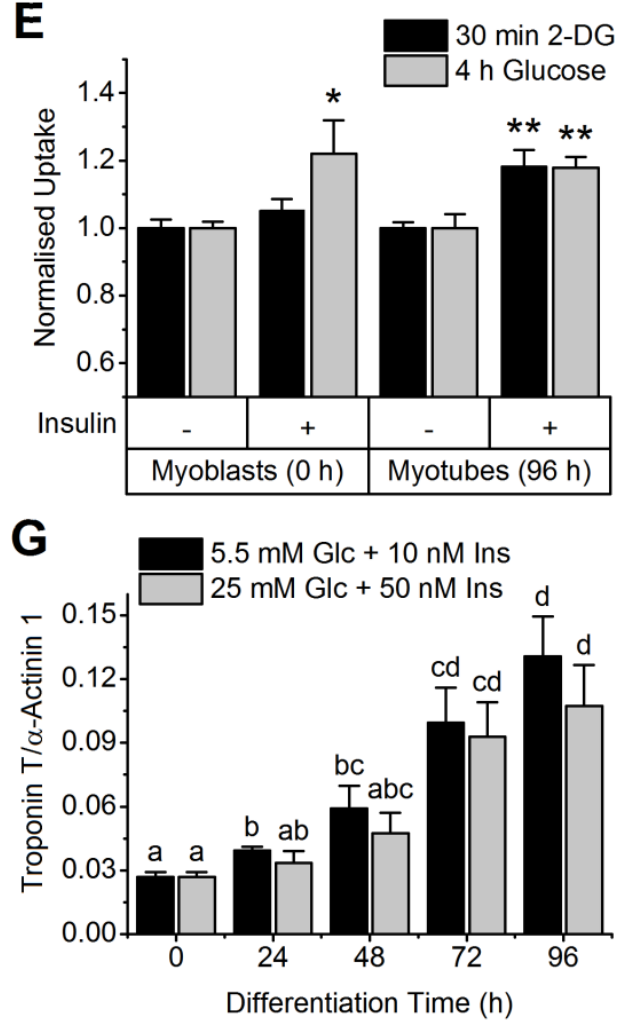

I

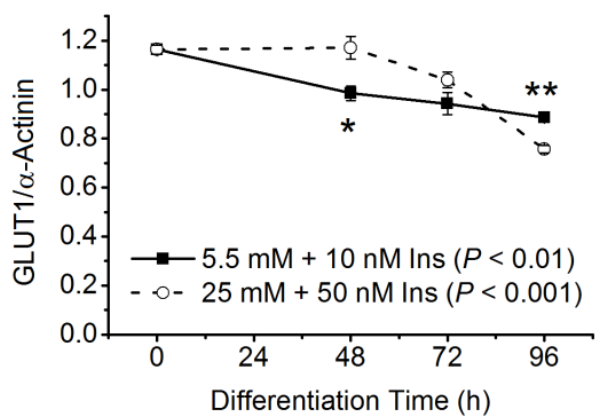

-14 - 


\section{Figure 1: LHCN-M2 myoblasts differentiate to insulin-responsive myotubes.}

Myoblasts were grown to confluence, and then in $5.5 \mathrm{mM}$ glucose and 2\% serum only for 96 $\mathrm{h}$. Images were taken daily using an inverted microscope at 10X magnification (A). Troponin $\mathrm{T}$ and $\alpha$-actinin 1 proteins were quantified by automated capillary Western blotting (for setup see Fig. S1) using total cell lysates sampled during the differentiation procedure. Mean \pm SEM $(\mathrm{N}=3)(B)$. Differentiated myotubes were starved of glucose and serum for $4 \mathrm{~h}$ and then incubated with various insulin concentrations and 2-[ $\left[{ }^{14} \mathrm{C}(\mathrm{U})\right]-$-deoxy-D-glucose $(2-\mathrm{DG}$; $0.55 \mathrm{mM} ; 0.15 \mu \mathrm{Ci} / \mathrm{ml})$ for $30 \mathrm{~min}(\mathrm{C})$ or $\mathrm{D}-\left[{ }^{14} \mathrm{C}(\mathrm{U})\right]$-glucose $(0.55 \mathrm{mM} ; 0.2 \mu \mathrm{Ci} / \mathrm{ml})$ for $4 \mathrm{~h}$ (D). Data are corrected against a standard curve for ${ }^{14} \mathrm{C}$-label and presented as $\mu \mathrm{g}$ sugar/mg total protein. Uptake of 2-[1- $\left.{ }^{14} \mathrm{C}(\mathrm{U})\right]$-deoxy-D-glucose or D- $\left[{ }^{14} \mathrm{C}(\mathrm{U})\right]$-glucose with and without 25 or $100 \mathrm{nM}$ insulin respectively was measured in myotubes and myoblasts (E). All uptake data are mean $\pm \operatorname{SEM}(\mathrm{N} / \mathrm{n}=4 / 12$ (C); 5/24 (D); 4/12 (E)). After differentiation for 96 $\mathrm{h}$ in $5.5 \mathrm{mM}$ glucose or $25 \mathrm{mM}$ glucose with various concentrations of insulin, 2', 7'dichlorofluorescin (DCF) fluorescence was measured after incubation with $10 \mu \mathrm{M} 2^{\prime}, 7^{\prime}$ dichlorofluorescin diacetate (DCFH-DA) in PBS for $20 \mathrm{~min}$. Mean $\pm \mathrm{SEM}(\mathrm{N} / \mathrm{n}=3 / 18)(\mathrm{F})$. Troponin T (G), GLUT4 (H) and GLUT1 (I) protein, all relative to $\alpha$-actinin 1, were measured in total cell lysates of myotubes differentiated in $5.5 \mathrm{mM}$ glucose (Glc) and $10 \mathrm{nM}$ insulin (Ins) or $25 \mathrm{mM}$ glucose and $50 \mathrm{nM}$ insulin. Linearity of responses and assay setups are shown in Fig. S1-3. Data are mean $\pm \operatorname{SEM}(\mathrm{N}=3)$. Different letters denote $p<0.05,{ }^{*} p<$ $0.05, * * p<0.01, * * * p<0.001$ for differences between treatments or time-points accordingly and $p$-values on figures are for differences between all points in each group. 
A

Ferulic acid 4-O-sulfate

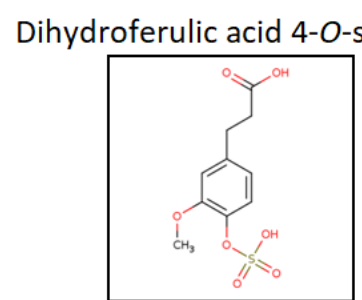

Dihydroferulic acid
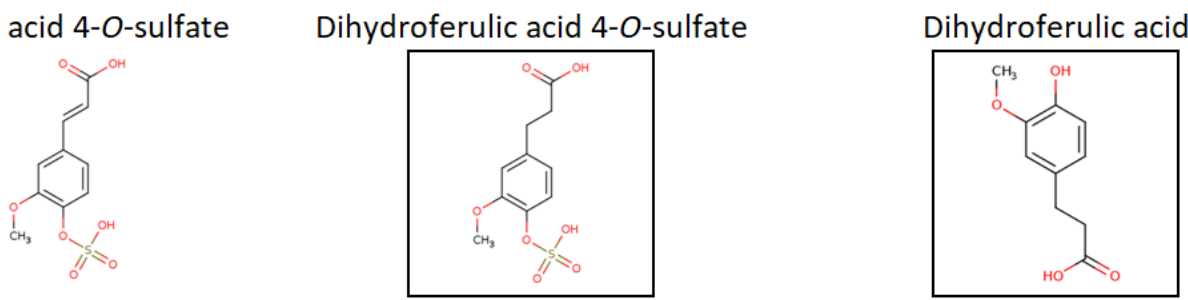

B Quercetin 3'-O-sulfate

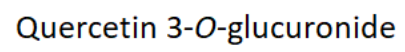

Kaempferol 3-O-glucuronide
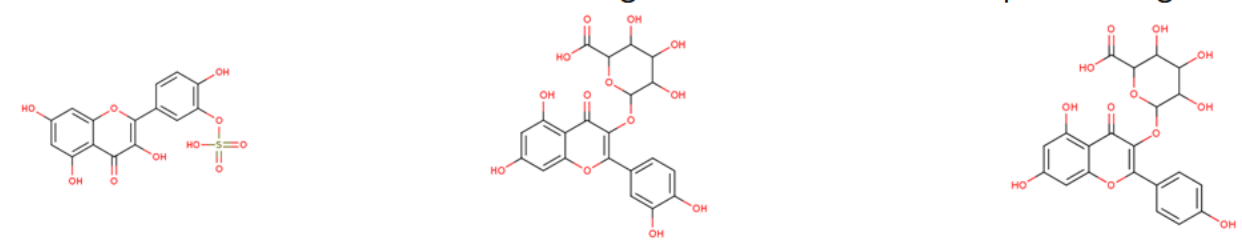

C

trans-Resveratrol

4'-O-glucuronide

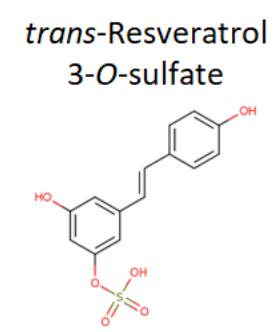

trans-Resveratrol

3-O-glucuronide
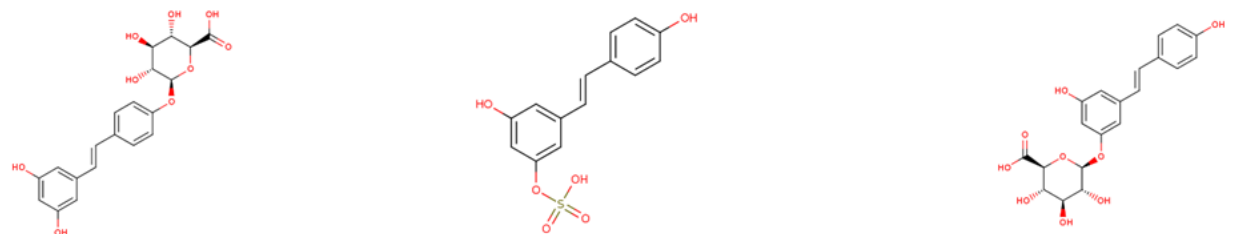

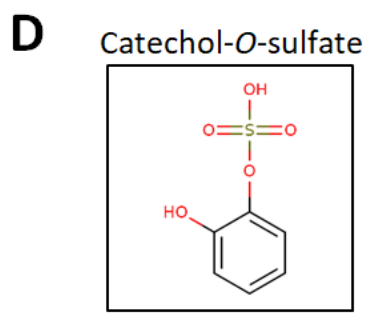

4-Methylgallic acid 3-O-sulfate

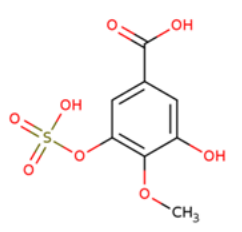

4-Methylcatechol-O-sulfate

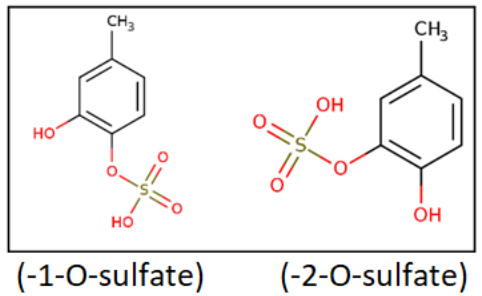

(-1-O-sulfate)

Vanillic acid 4-O-sulfate

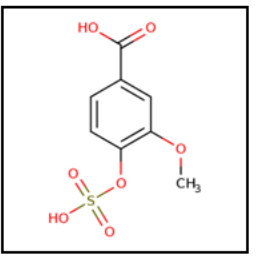

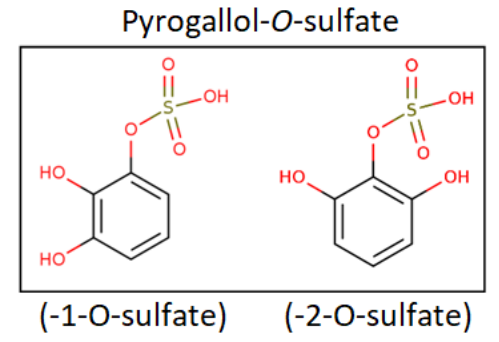

Isovanillic acid 3-O-sulfate

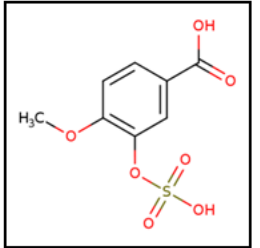

Figure 2: Phenolic metabolites investigated for potential roles in modulating glucose uptake and metabolism in human skeletal muscle.

Derivatives of ferulic acid (A); flavonol conjugates (B); resveratrol conjugates (C); phenolic sulfates in circulation after the consumption of berries (D). Boxed compounds originate predominantly from colonic microbiota metabolism, unboxed in the small intestine. 

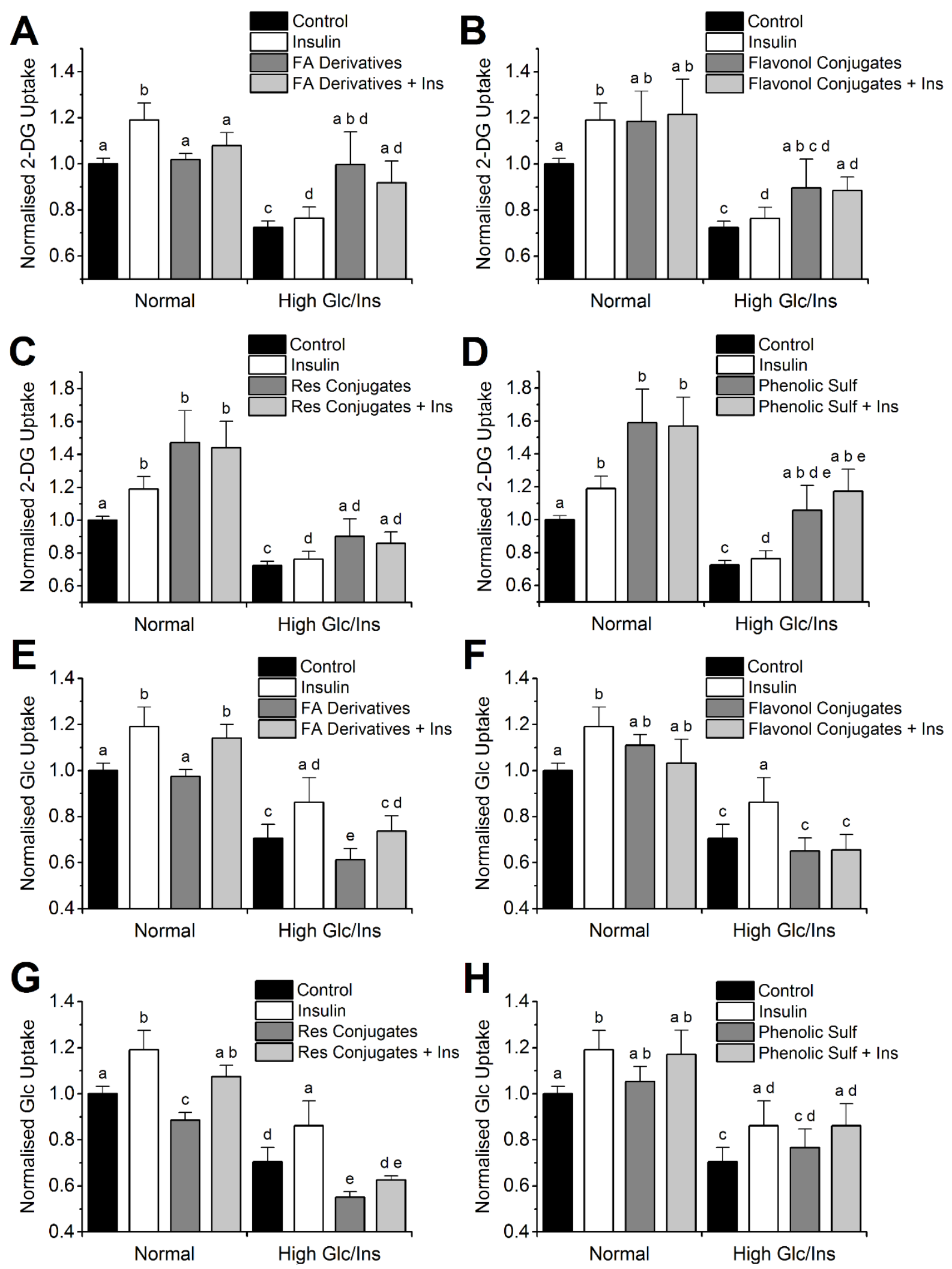


\section{Figure 3: Effect of metabolite mixtures on $2-\left[1-{ }^{14} \mathrm{C}(\mathrm{U})\right]$-deoxy-D-glucose and $D-\left[{ }^{14} \mathrm{C}(\mathrm{U})\right]-$}

glucose uptake and metabolism in LHCN-M2 myotubes.

Myotubes, differentiated for $96 \mathrm{~h}$ in $5.5 \mathrm{mM}$ glucose and $10 \mathrm{nM}$ insulin (normal) or in 25 $\mathrm{mM}$ glucose and $50 \mathrm{nM}$ insulin (high Glc/Ins), were starved of glucose, insulin and serum, in the presence of indicated compounds or DMSO, for $4 \mathrm{~h}$. Myotubes were then incubated with a DMSO control, $100 \mathrm{nM}$ insulin (Ins), the same compounds, or the same compounds plus $100 \mathrm{nM}$ insulin, with $0.15 \mu \mathrm{Ci} / \mathrm{ml} 2-\left[{ }^{14} \mathrm{C}(\mathrm{U})\right]$-deoxy-D-glucose (2-DG; $0.55 \mathrm{mM}$ ) for $30 \mathrm{~min}$ (A-D); or with the same protocol but with $25 \mathrm{nM}$ insulin and $0.2 \mu \mathrm{Ci} / \mathrm{ml} \mathrm{D}-\left[{ }^{14} \mathrm{C}(\mathrm{U})\right]$ glucose (Glc; $0.55 \mathrm{mM})$ for $4 \mathrm{~h}(\mathrm{E}-\mathrm{H})$. Data were normalized to the DMSO-containing normal Glc/Ins controls and shown as mean $\pm \operatorname{SEM}(\mathrm{N} / \mathrm{n}=4 / 12)$. Ferulic acid (FA) derivatives - FA4S, DHFA-4S and DHFA, all at $2 \mu \mathrm{M}(\mathrm{A})$; flavonol conjugates - Q3S, Q3G and K3G, all at 2 $\mu \mathrm{M}$ (B); resveratrol (Res) conjugates - R4G, R3S and R3G, all at $2 \mu \mathrm{M}(\mathrm{C})$; phenolic sulfates (Phenolic Sulf) - CS, MCS, PS, MGS, VAS and IVAS, all at $5 \mu \mathrm{M}$ (D). Different letters above bars indicate $p<0.05$ between groups. 

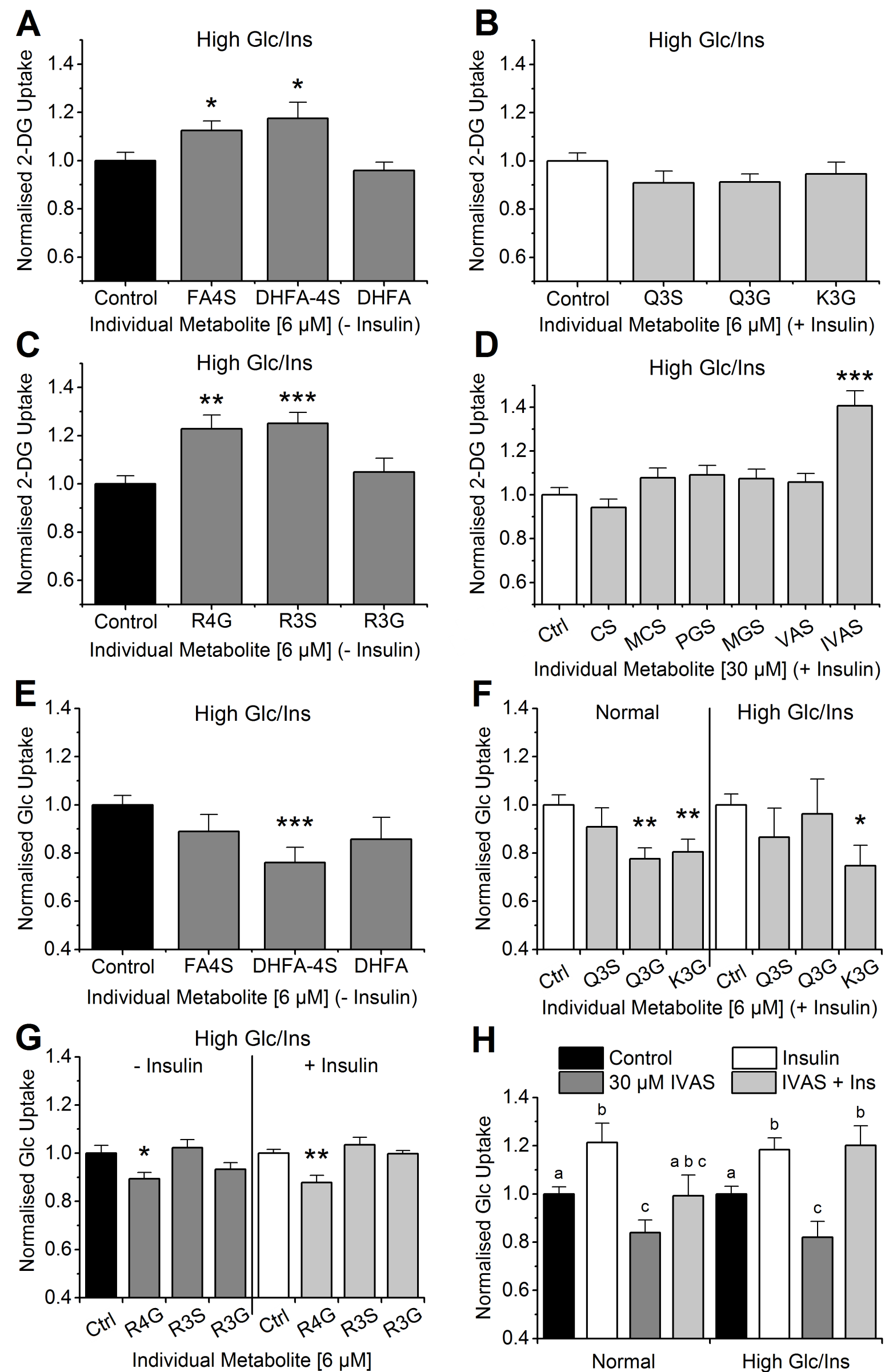


\section{Figure 4: Effect of individual compounds on 2-deoxy-D-glucose uptake and glucose}

metabolism.

Myotubes, differentiated for $96 \mathrm{~h}$ in $25 \mathrm{mM}$ glucose and $50 \mathrm{nM}$ insulin (High Glc/Ins), were starved of glucose, insulin and serum in the presence of a metabolite or DMSO control (Ctrl) for $4 \mathrm{~h}$, and then incubated with the same compound $\pm 100 \mathrm{nM}$ insulin and $0.15 \mu \mathrm{Ci} / \mathrm{ml} 2$ $\left[{ }^{14} \mathrm{C}(\mathrm{U})\right]$-deoxy-D-glucose (0.55 mM; 2-DG) for $30 \mathrm{~min}$ (A-D). Myotubes, differentiated for $96 \mathrm{~h}$ in $5.5 \mathrm{mM}$ glucose and $10 \mathrm{nM}$ insulin (normal) or in high Glc/Ins, were starved of glucose, insulin and serum in the presence of a metabolite or DMSO control (labelled D) for $4 \mathrm{~h}$, then incubated with the same compound $\pm 25 \mathrm{nM}$ insulin (Ins) and $0.2 \mu \mathrm{Ci} / \mathrm{ml} \mathrm{D-}$ $\left[{ }^{14} \mathrm{C}(\mathrm{U})\right]$ glucose $(0.55 \mathrm{mM}$; Glc) for $4 \mathrm{~h}(\mathrm{E}-\mathrm{H})$. All data were normalized to the DMSO and are shown as mean $\pm \operatorname{SEM}(\mathrm{N} / \mathrm{n}=4 / 12) .{ }^{*} p<0.05,{ }^{*} p<0.01, * * * p<0.001 v s$ the controls accordingly. Different letters above bars $(\mathrm{H})$ indicate $p<0.05$ between groups. 

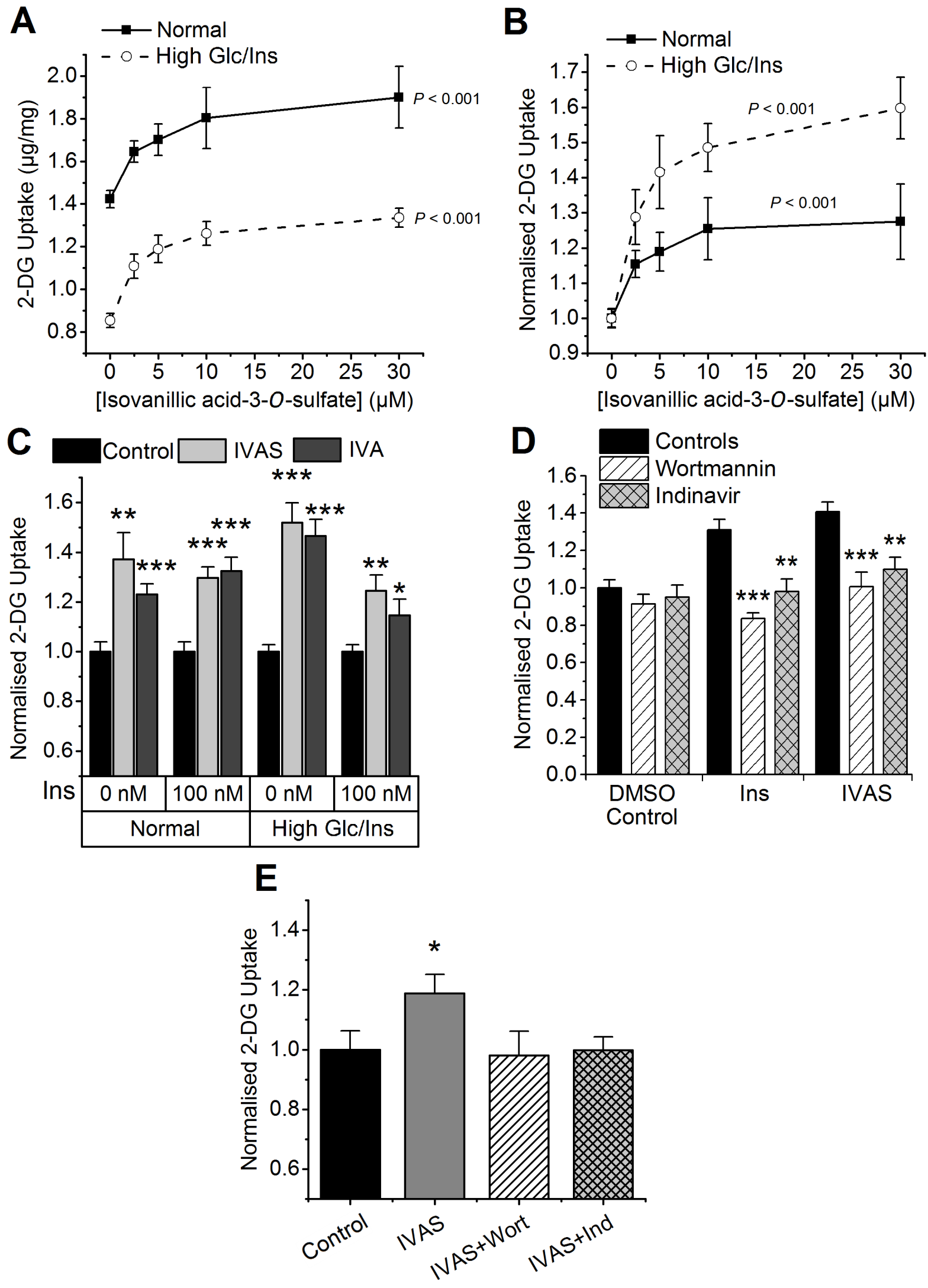


\section{Figure 5: Mechanism of the effect of IVAS on 2-[ $\left[{ }^{14} \mathrm{C}(\mathrm{U})\right]$-deoxy-D-glucose uptake.}

Myotubes, differentiated for $96 \mathrm{~h}$ in $5.5 \mathrm{mM}$ glucose and $10 \mathrm{nM}$ insulin (Normal) or in 25 $\mathrm{mM}$ glucose and $50 \mathrm{nM}$ insulin (High Glc/Ins), were starved of glucose, insulin and serum in the presence of various concentrations of IVAS for $4 \mathrm{~h}$, followed by the same IVAS treatment together with $0.15 \mu \mathrm{Ci} / \mathrm{ml} 2-\left[{ }^{14} \mathrm{C}(\mathrm{U})\right]$-deoxy-D-glucose (0.55 mM; 2-DG) for $30 \mathrm{~min}$. Panel A shows the absolute 2-DG uptake, whereas panel B shows the same data but normalized to basal level for each condition, to enable visualization of the relative effect of IVAS. Panel C shows the same treatment but with $30 \mu \mathrm{M}$ IVAS or $30 \mu \mathrm{M}$ isovanillic acid (IVA) $\pm 100 \mathrm{nM}$ insulin in the $30 \mathrm{~min}$ incubation. The effects of $5 \mu \mathrm{M}$ wortmannin (Wort) or $20 \mu \mathrm{M}$ indinavir (Ind) on 2-DG uptake, stimulated by $100 \mathrm{nM}$ insulin (Ins) or $30 \mu \mathrm{M}$ IVAS (30 min incubations), were explored against the DMSO-treated controls (D). Myotubes were also treated with IVAS acutely, i.e. bypassing the $4 \mathrm{~h}$ pre-treatment, in the presence of Wort or Ind during the $30 \mathrm{~min}$ incubation with $0.55 \mathrm{mM} 2-\left[1-{ }^{14} \mathrm{C}(\mathrm{U})\right]$-deoxy-D-glucose (E). All data are shown as mean $\pm \operatorname{SEM}(\mathrm{N} / \mathrm{n}=4 / 12) .{ }^{*} p<0.05, * * p<0.01, * * * p<0.001 v s$ controls accordingly. 

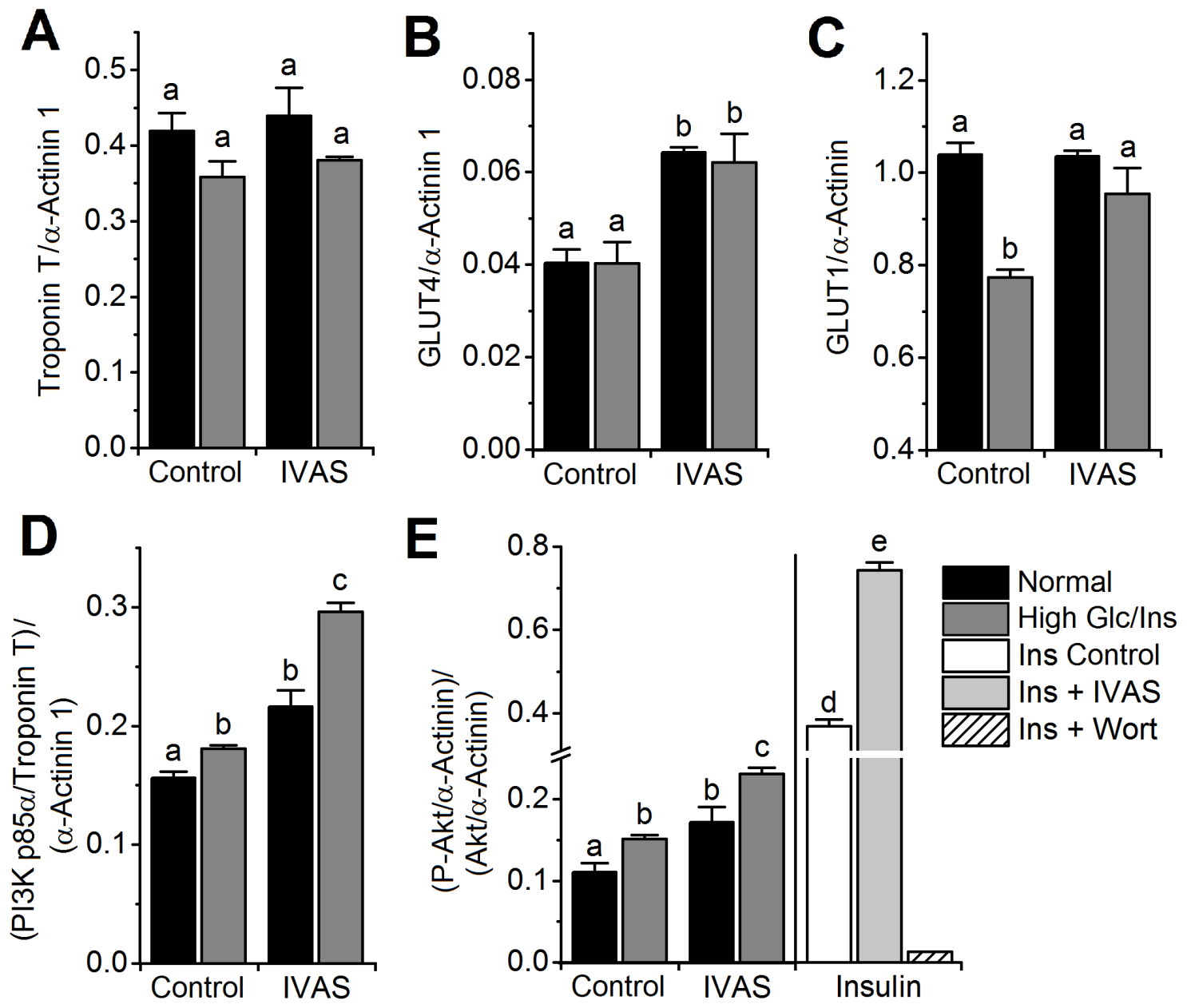

Figure 6: IVAS upregulates GLUTs and PI3K, and activates Akt.

Myotubes were differentiated in $5.5 \mathrm{mM}$ glucose and $10 \mathrm{nM}$ insulin (Normal) or $25 \mathrm{mM}$ glucose and $50 \mathrm{nM}$ insulin (High Glc/Ins) and then treated with $30 \mu \mathrm{M}$ IVAS or DMSO for 4 $\mathrm{h}$ while starved of glucose, insulin and serum. Troponin T protein (A), GLUT4 protein (B) GLUT1 protein (C) and PI3K p85 $\alpha$ protein (D) were measured using automated capillary Western blotting relative to $\alpha$-actinin or $\alpha$-actinin 1 , or to troponin T and $\alpha$-actinin accordingly. The response to the antibodies was optimized in the linear dose-response range (Fig. S1-S4). After the $4 \mathrm{~h}$ starvation/incubation with IVAS or DMSO, myotubes were incubated with $0.55 \mathrm{mM}$ glucose and $30 \mu \mathrm{M}$ IVAS, $100 \mathrm{nM}$ insulin (Ins, positive control), IVAS and insulin combined, insulin and $5 \mu \mathrm{M}$ wortmannin (Wort, negative control), or DMSO controls for $15 \mathrm{~min}$. Total lysates were analyzed in the same way, with Akt or phospho-Akt (Ser473) (P-Akt) and $\alpha$-actinin antibodies (optimized as shown in Fig. S5) (E). All data shown are mean ratios of the target protein/loading control $\pm \operatorname{SEM}(\mathrm{N}=3)$. Different letters above bars denote where $p<0.05$ between treatments. 


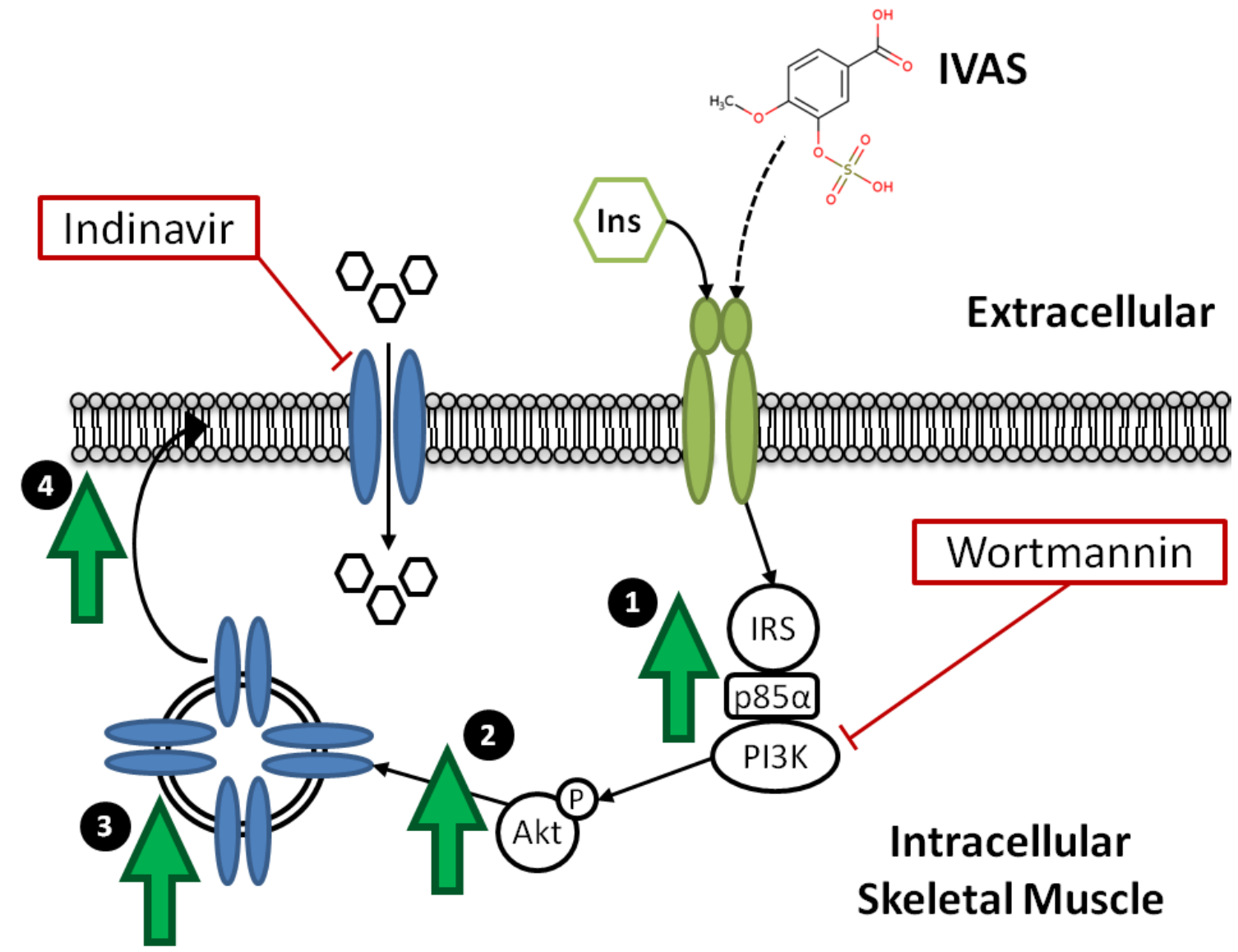

Figure 7: Proposed mechanisms of action by which IVAS increases glucose uptake and metabolism in human skeletal muscle.

Numbered green arrows show sites of action of IVAS: 1) PI3K (p85a) is upregulated; 2) Akt phosphorylation is acutely increased; 3) total GLUT4 is upregulated; 4) GLUT4-mediated glucose uptake is increased. Plasma membrane proteins: blue - GLUT4 (also shown stored in cytosolic vesicle); light green - insulin receptor. Ins - insulin; P - phosphate; hexagons represent glucose. 


\section{Discussion}

Human immortalized LHCN-M2 myoblast differentiation to myotubes was accompanied by increased troponin T expression (33) while $\alpha$-actinin protein, which increases with Z-line formation but not before, was unchanged (40), both as expected. The myotubes were responsive to insulin, a characteristic of skeletal muscle (41). GLUT4 increased with differentiation while GLUT1 decreased, consistent with previous data (42). Differentiation in high glucose and high insulin increased DCF-fluorescence, a marker of intracellular ROS levels in the LHCN-M2 myotubes, although the overall rate of differentiation was unchanged. The two conditions, a normal or high glucose and insulin environment, were chosen for many of the experiments here, to compare effects amplified in a higher oxidative stress environment.

The gut microbiome produces a large number of small molecules from its supply of nutrients and other components which reach it via the small intestine. One characteristic is that there are multiple catabolites from a single food source or even from a pure compound $(43,44)$. After consumption of coffee, for example, the gut microbiome metabolites predominantly include DHFA, DHFA-sulfate and FA-sulfate (44), and these are derived from chlorogenic acids. Whole grains, including cereal brans, give comparable profiles derived from covalently bound phenolic acids $(45,46)$. We therefore tested mixtures of some of these metabolites, including conjugates, characteristically derived from either the small intestine or from the colonic microbiota (Fig. 2). Using a non-metabolizable derivative of glucose, 2-DG, we found that some combinations of metabolites such as ferulic acid derivatives showed an insulin-like effect in cells differentiated in high glucose and high insulin conditions, but not in normal glucose/insulin; while others, such as the resveratrol conjugates and the phenolic acid sulfates mixture, produced a robust effect under both normal and high Glc/Ins. Using labelled glucose as a marker allows the metabolism of glucose to be assessed, leading to end products such as $\mathrm{CO}_{2}$ or lactate, which are expelled into the medium, or glycogen, which is

stored intracellularly. Some of the metabolite mixtures lowered the amount of ${ }^{14} \mathrm{C}$-label intracellularly, which, together with the enhanced uptake of glucose evident from the 2-DG data, indicates a stimulation of glucose metabolism leading to enhanced secretion of the ${ }^{14} \mathrm{C}$ label (47). 
For the ferulic acid mixture, only the sulfated conjugates, FA4S and DHFA-4S, were responsible for the stimulation of glucose transport and the latter alone for the increased metabolism. DHFA-4S, the most active component, is derived almost entirely following the action of the gut microbiota on a range of substrates to produce DHFA, which, after absorption in the colon, is then sulfated by sulfotransferases in the liver. Unconjugated ferulic acid has been shown to increase (deoxy)glucose uptake in primary porcine and human myotubes $(48,49)$ as well as into muscle L6 myotubes while upregulating GLUT4 and PI3K (50). However, unconjugated ferulic acid is not a microbial metabolite and does not exist in plasma in the free form in significant concentrations (44). These data show that the production of DHFA-4S from the gut microbiome could affect glucose uptake and metabolism in muscle, but that the effect would be mostly evident at chronic high glucose concentrations, which exist in metabolic syndrome with impaired glucose tolerance or in diabetes.

The mixture of flavonol conjugates, or individual compounds, exerted only minimal effects on muscle cell uptake of glucose or 2-DG. These conjugates are products of small intestine and hepatic metabolism, and are not derived from the gut microbiota $(18,20)$. At very high concentrations, flavonol aglycones were claimed to increase 2-DG uptake in L6 myotubes (51) and quercetin increased glucose uptake via AMPK activation independently of insulin in $\mathrm{C} 2 \mathrm{C} 12$ and L6 muscle cells $(52,53)$, but these aglycones are not present at sufficient concentration in plasma to exert a significant effect (54).

Resveratrol is a highly bioactive molecule that is absorbed in the small intestine and its presence in blood does not depend on action of the gut microbiota (18). The resveratrol conjugates increased basal 2-DG uptake and glucose metabolism in both normal and high Glc/Ins myotubes, restoring the lowered 2-DG transport and negating the longer term effect of insulin in the latter. The increased transport was attributable to R4G and R3S, but only R4G was shown to increase metabolism. Resveratrol aglycone has been shown previously to increase (deoxy)glucose uptake in muscle, possibly involving AMPK. Elevated uptake by resveratrol in rodent myotubes was dependent on GLUT4 translocation through activation by sirtuins and AMPK and involving PI3K/Akt pathway activation $(55,56)$. 
The phenolic sulfates are almost entirely derived from the action of the gut microbiota (29), with subsequent hepatic sulfation. They increased basal 2-DG uptake in normal and high Glc/Ins myotubes and even potentiated the effect of insulin in the latter. Of the compounds tested here, this group displayed the most prominent activity, however, the mixture did not have an effect of glucose metabolism. The increased transport was solely due to IVAS, which also increased basal metabolism in normal and high Glc/Ins when tested as a single metabolite. There are very few reports on the biological activity of IVAS. It has been identified as a plasma metabolite following consumption of berries or cyanidin 3-O-glucoside $(29,57)$ and as a phase II conjugate of protocatechuic acid (PCA) (58), but in those studies was (analytically) undistinguishable from VAS. PCA dose-dependently increased (deoxy)glucose uptake in primary human muscle cells (49), and mimics insulin by activating the insulin receptor to increase glucose uptake in human adipocytes (59). PCA and its metabolite(s) may have an effect on both pathways that stimulate GLUT4 translocation on L6 myotubes (60).

In our study, IVAS-stimulated 2-DG uptake was dose-dependent and, as for insulin, exhibited a greater effect in the high Glc/Ins myotubes. Inhibition of IVAS-stimulated uptake by wortmannin and indinavir indicated that the mechanism was dependent on PI3K signaling and GLUT4 translocation (Fig. 7). IVAS also upregulated GLUT4 and PI3K p85 $\alpha$, as well as activating Akt in the short term. IVAS is relatively hydrophilic with a $\operatorname{LogP}$ of -0.73 , and so would not enter the myotubes without facilitated transport, while IVA is more hydrophobic (LogP of 1.81) and could enter cells by passive diffusion (61). We therefore suggest that the most likely action of IVAS and IVA is on the insulin receptor on the surface of the LHCNM2 cell, since these cells do not express the OATs (see supplementary table S1) which are necessary for uptake of molecules such as IVAS (62).

The data presented here has shown that conjugated catabolites, derived from the action of gut microbiota, affect glucose uptake and metabolism in human skeletal LHCN-M2 myotubes. Compounds such as DHFA-4S and IVAS were particularly potent, and formation of these compounds absolutely require action of the gut microbiota; DHFA and derivatives are almost absent in ileostomist subjects who have had their colon surgically removed (63). Studies on foods from which IVAS is known to be ultimately formed by the gut microbiota have shown some beneficial effects in vivo. Supplementation with blueberry bioactive compounds for 6 
weeks improved insulin sensitivity in obese, insulin-resistant participants (64) and, when bread was consumed with berries, less insulin was needed to control the post-prandial glucose (65).

Interactions between colonic microbiota and host tissues mediated by metabolites such as SCFA have been studied previously, in particular for butyrate (13), which has the ability to act on many tissues including muscle $(7,14)$. The work presented here identifies novel effects of alternative gut microbiome-derived molecules on muscle cells which could have implications on the interaction with skeletal muscle tissue in vivo. Although some activity was observed on phenolic metabolites produced during absorption by the small intestine, the most active molecules were derived from metabolism involving the gut microbiota. Importantly, these molecules have been detected in blood in humans, and their pathways of post-prandial metabolism have been well described $(29,44)$. We have focused here on the effects on glucose uptake and metabolism, as accurate and timely regulation of these processes is vital for correct functioning of muscle cells. With the skeletal muscle accounting for up to $75 \%$ of postprandial glucose disposal (4), improving insulin-stimulated glucose uptake in muscle cells through nutritional regulation of the gut microbiome could lead to improved systemic glucose metabolism and enhanced muscle performance with concurrent beneficial effects for the host.

\section{Acknowledgements}

We acknowledge the platform for the immortalization of human cells of the Institut de Myologie in Paris and thank Dr Samantha Gardner for helping to establish the muscle cells in our lab. We acknowledge funding from the European Research Council for an advanced grant (POLYTRUE? 322467).

\section{Author Contributions}

M. J. Houghton designed and performed research, analyzed data and wrote the paper; A. Kerimi designed research, contributed training and expertise and edited the paper; V. Mouly contributed the muscle cells and edited the paper; S. Tumova contributed training and expertise and edited the paper; G. Williamson designed research and wrote the paper. 


\section{Supplementary Material}

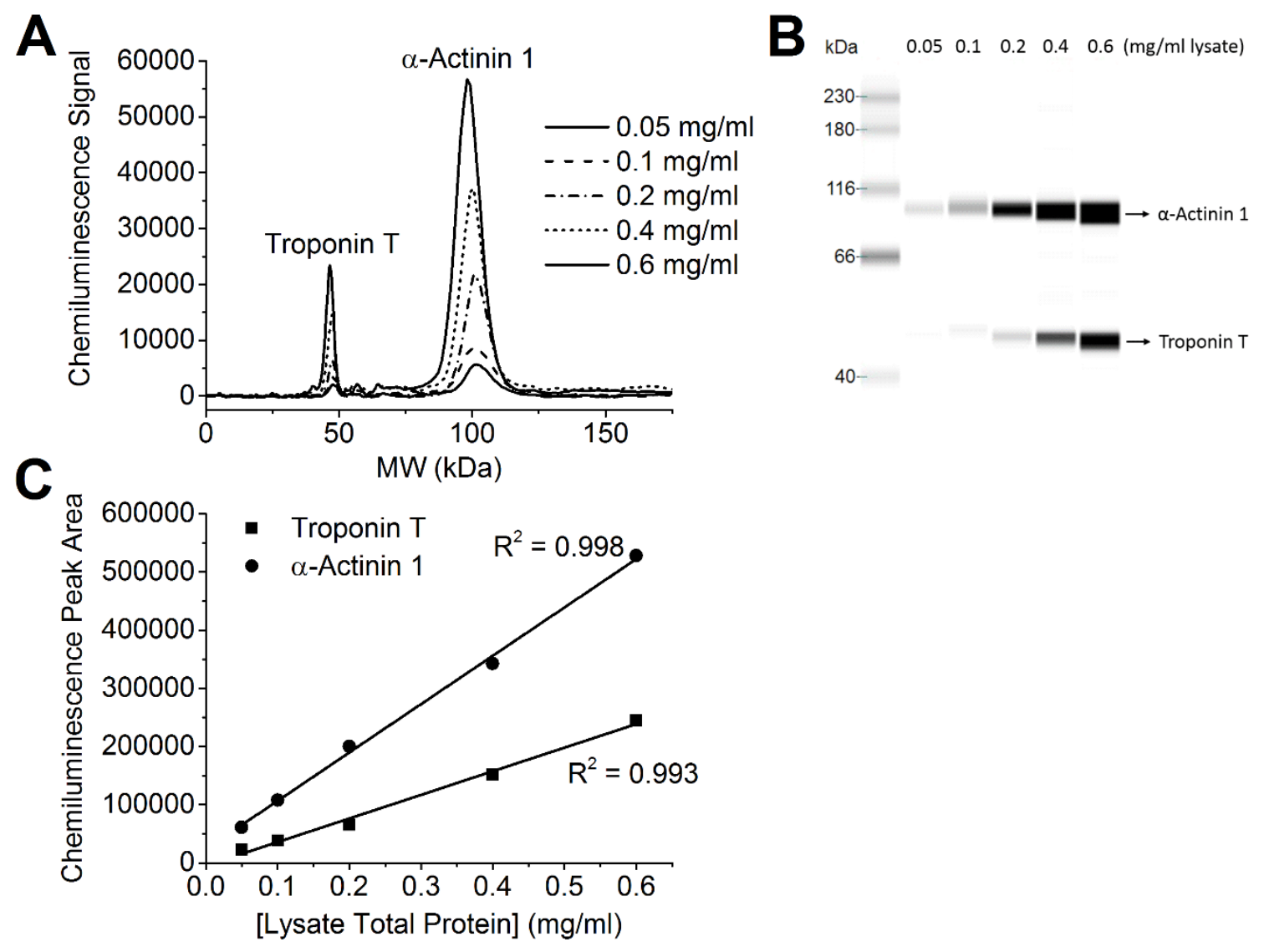

Figure S1: Antibody validation for Western analysis of troponin $T$ and $\alpha$-actinin 1.

Different total protein concentrations of differentiated LHCN-M2 whole cell lysates were analyzed for troponin $\mathrm{T}$ and $\alpha$-actinin 1 and both antibodies were run in the same capillary on the automated western blotting system "WES" (ProteinSimple) to test for linearity of signals. Electropherogram view (A) and gel-blot (lane) view (B). The peak areas were used to establish a standard curve for each antibody when duplexed (C). 

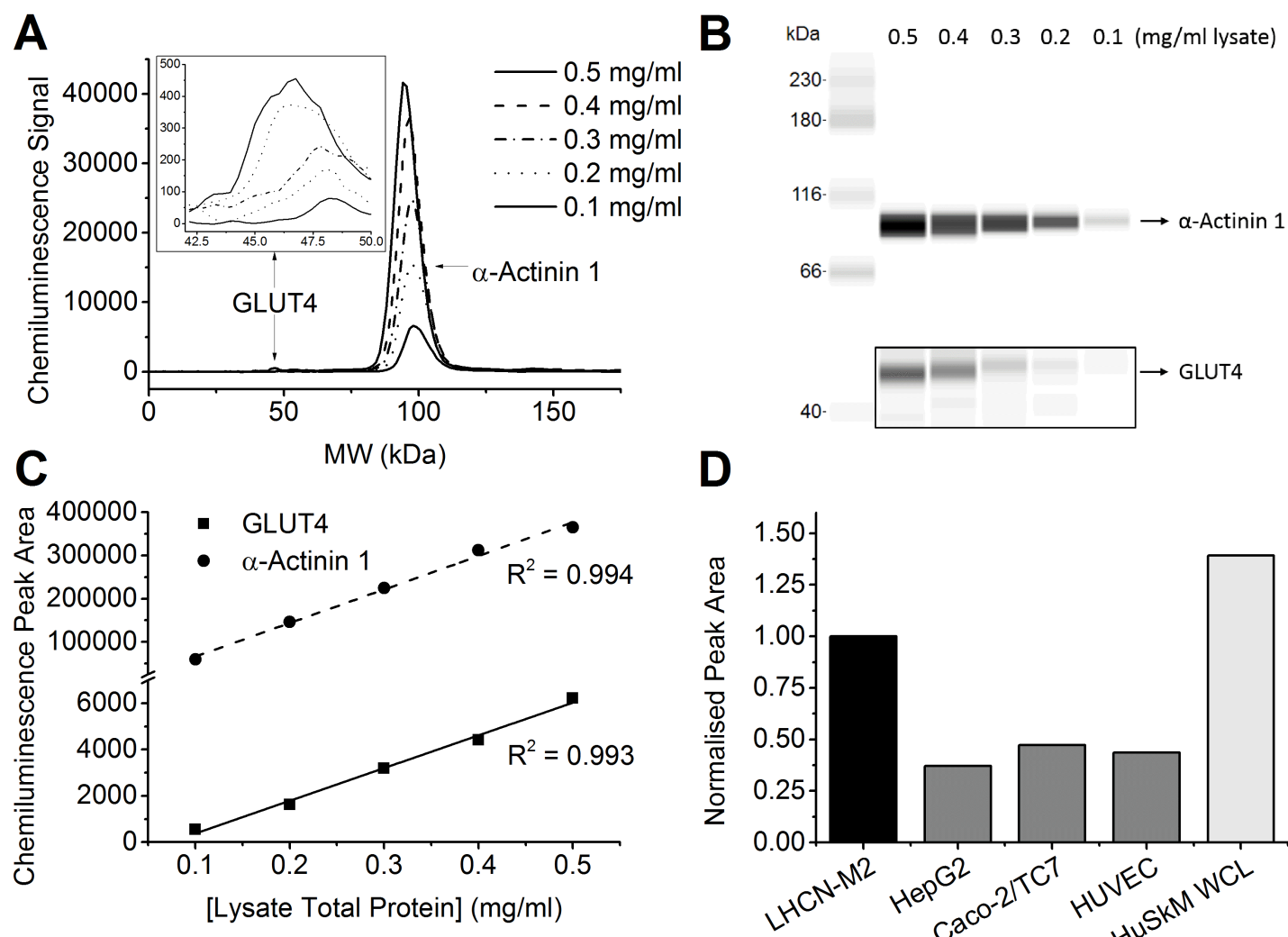

D

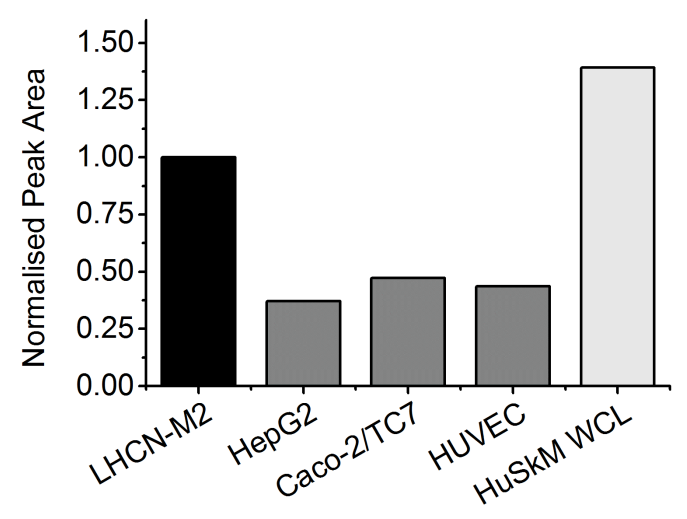

Figure S2: Antibody validation for Western analysis of GLUT4 and $\alpha$-actinin 1.

Different total protein concentrations of differentiated LHCN-M2 whole cell lysates were analyzed for GLUT4 and $\alpha$-actinin 1 and both antibodies were run in the same capillary on the automated western blotting system "WES" (ProteinSimple) to test for linearity of signals. Electropherogram view (A) and gel-blot (lane) view (B). The peak areas were used to establish a standard curve for each antibody when duplexed (C). The specificity of the peak at $\sim 47 \mathrm{kDa}$ was supported by running the LHCN-M2 lysate alongside a human skeletal muscle whole cell lysate (HuSkM WCL) as a positive control and HepG2, Caco-2/TC7 and HUVEC total cell lysate negative controls (D). 


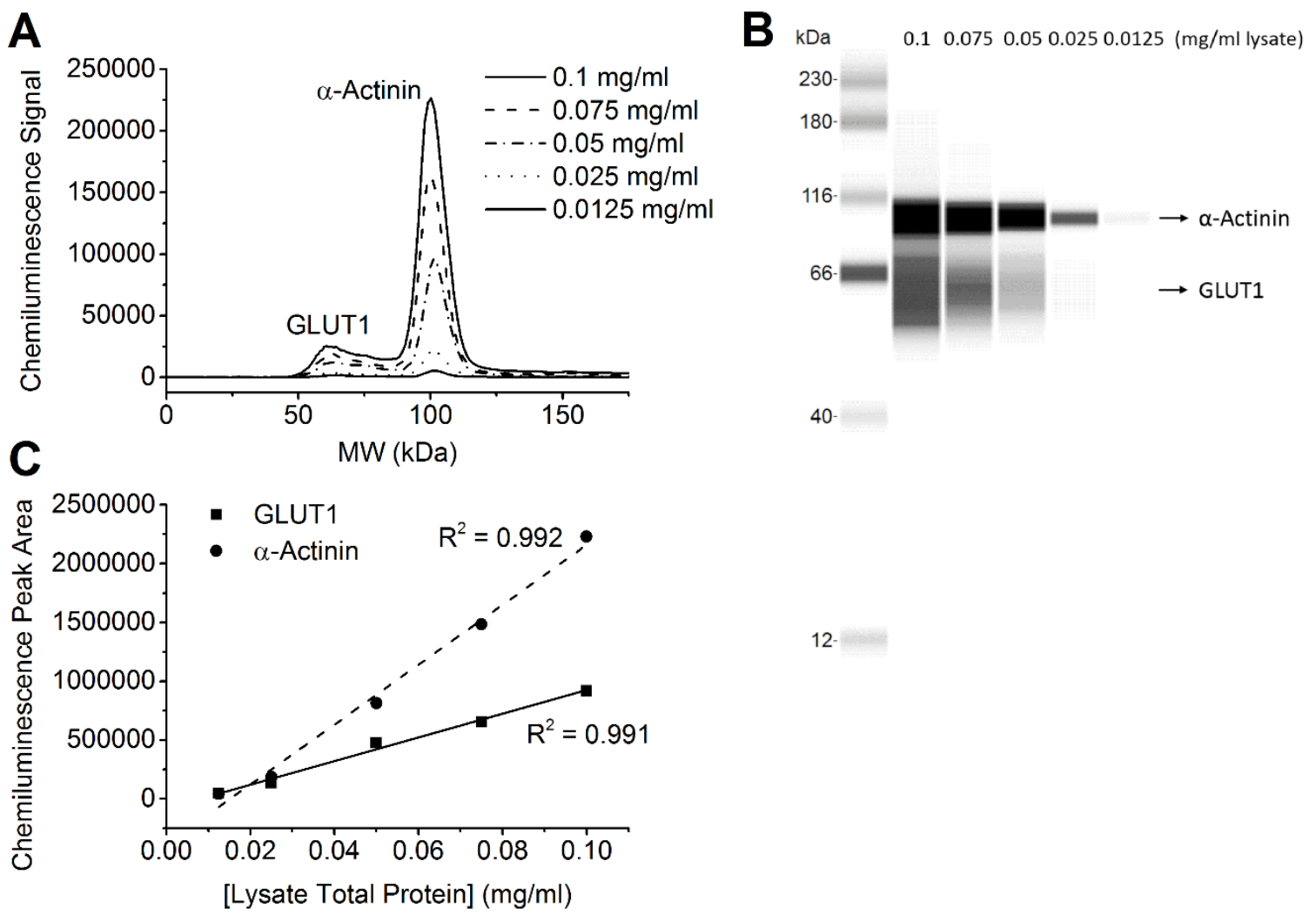

Figure S3: Antibody validation for Western analysis of GLUT1 and $\alpha$-actinin protein.

Different total protein concentrations of differentiated LHCN-M2 whole cell lysates were analyzed for GLUT1 and $\alpha$-actinin and both antibodies were run in the same capillary on the automated western blotting system "WES" (ProteinSimple) to test for linearity of signals. Electropherogram view (A) and gel-blot (lane) view (B). The peak areas were used to establish a standard curve for each antibody when duplexed (C). 
A

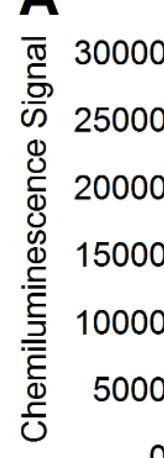
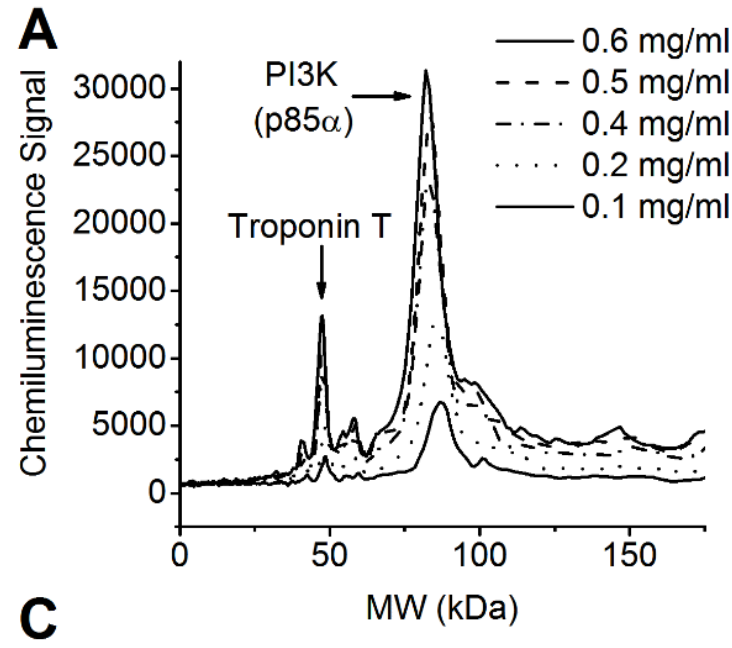

$$
\text { MW (kDa) }
$$

đ্

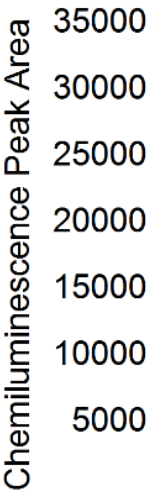

\section{- Troponin T}

- $\operatorname{PI3K}(p 85 \alpha)$
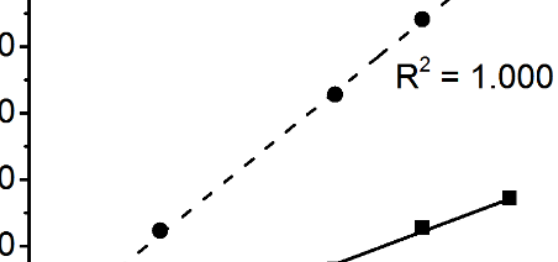

0

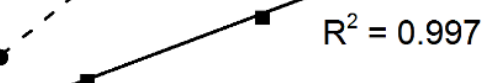

$\begin{array}{llllll}0.1 & 0.2 & 0.3 & 0.4 & 0.5 & 0.6\end{array}$

[Lysate Total Protein] $(\mathrm{mg} / \mathrm{ml})$
B

$\begin{array}{llllll}\mathrm{kDa} & 0.6 & 0.5 & 0.4 & 0.2 & 0.1\end{array}$ ( $\mathrm{mg} / \mathrm{ml}$ lysate)

230 -

180

$116-$

$66-$

$\rightarrow \mathrm{PI} 3 \mathrm{~K}(\mathrm{p} 85 \alpha)$

$\rightarrow$ Troponin T

40

12

Figure S4: Antibody validation for Western analysis of regulatory unit p85a of PI3K and troponin $\mathbf{T}$ protein.

Differentiated LHCN-M2 whole cell lysates were analyzed with PI3K p85 $\alpha$ and troponin T antibodies at different concentrations run in the same capillary on the automated western blotting system "WES" (ProteinSimple) to test for linearity of signals. Electropherogram view (A) and gel-blot (lane) view (B). The peak areas were used to establish a standard curve for each antibody when duplexed (C). Note, troponin $\mathrm{T}$ was chosen as a loading control for PI3K p $85 \alpha$ because the MW of the latter is too close to that of $\alpha$-actinin (1). 

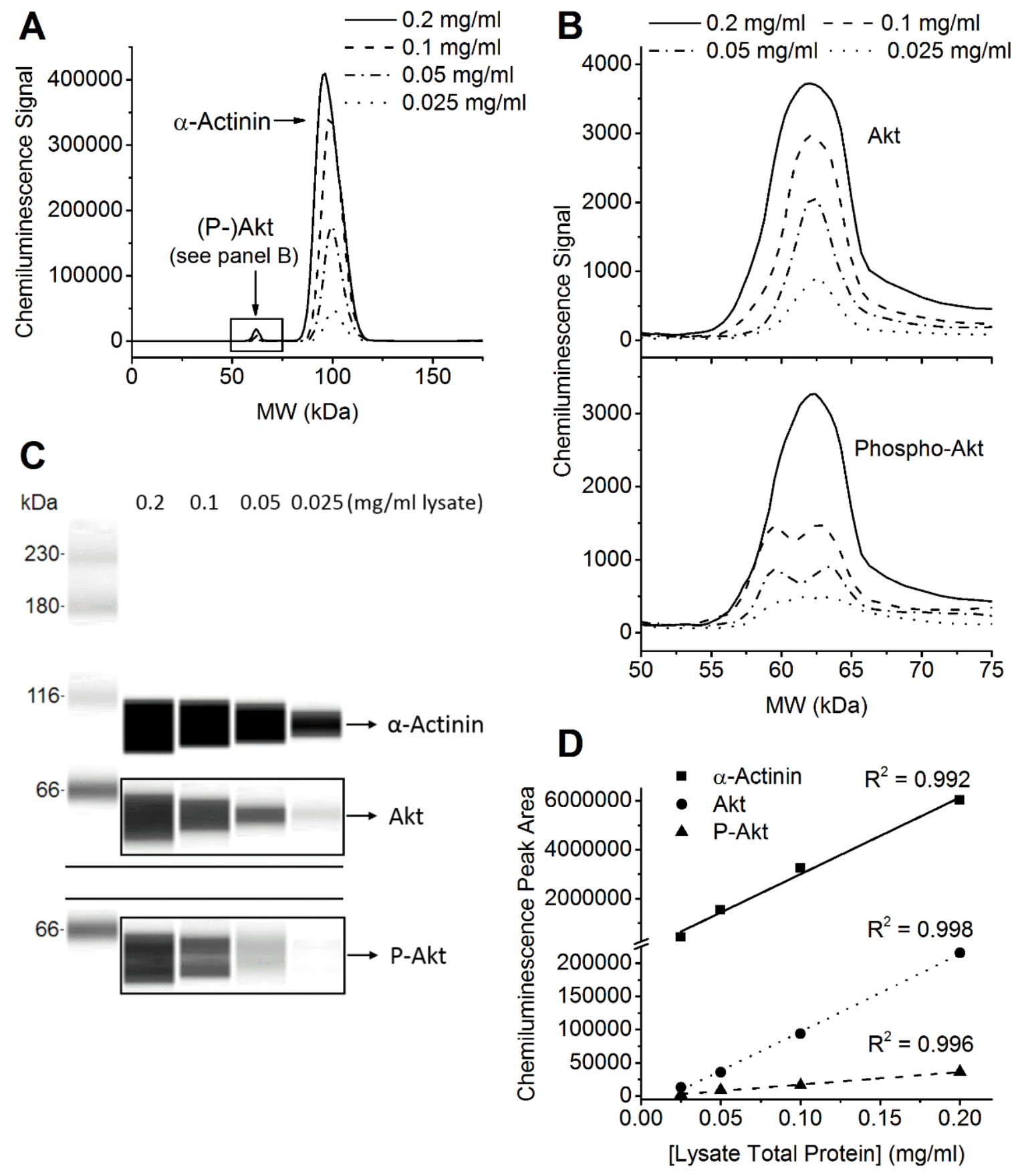

Figure S5: Antibody validation for Western analysis of Akt and p-Akt with $\alpha$-actinin.

Differentiated LHCN-M2 whole cell lysates were analyzed for total and phospho-Akt (P$\mathrm{Akt}$ ). Antibodies for Akt or P-Akt were run in the same capillary with $\alpha$-actinin on the automated western blotting system "WES" (ProteinSimple) to test for linearity of signals. Electropherogram view (A, B) and gel-blot (lane) view (C). The peak areas were used to establish a standard curve for each antibody when duplexed (C). Note, the $\alpha$-actinin curve consists of mean data of each of the curves run with Akt and P-Akt (D). 
Table S1: Relevant changes in mRNA of LHCN-M2 cells during differentiation*.

\begin{tabular}{|c|c|c|c|c|c|c|c|}
\hline \multirow{2}{*}{ Gene \# } & \multirow[t]{2}{*}{ Protein } & \multicolumn{2}{|c|}{ FPKM $^{1}$} & \multicolumn{2}{|c|}{$\begin{array}{l}\text { Ratio to } \\
\text { Actinin }\end{array}$} & \multicolumn{2}{|c|}{$\begin{array}{l}\text { Differentiation } \\
\text { fold-change }\end{array}$} \\
\hline & & Day 0 & Day 4 & Day 0 & Day 4 & FPKM & Ratio \\
\hline 181856 & GLUT4 & 0.05 & 7.29 & 0.0003 & 0.11 & 146 & 323 \\
\hline 117394 & GLUT1 & 126 & 58.8 & 0.83 & 0.86 & 0.46 & 1.03 \\
\hline 118194 & Troponin T2 (cardiac) & 74.5 & 1103 & 0.49 & 16.1 & 14.8 & 32.8 \\
\hline 72110 & $\alpha$-Actinin 1 & 152 & 68.8 & 1.00 & 1.00 & 0.45 & 1.00 \\
\hline 145675 & PI3K $\alpha$ & 7.85 & 9.93 & 0.05 & 0.14 & 1.26 & 2.80 \\
\hline 105221 & $\mathrm{Akt} 2$ & 45.1 & 33.3 & 0.30 & 0.48 & 0.74 & 1.63 \\
\hline 169047 & IRS1 & 13.7 & 11.8 & 0.09 & 0.17 & 0.86 & 1.91 \\
\hline 171105 & INSR & 3.54 & 5.64 & 0.02 & 0.08 & 1.59 & 3.53 \\
\hline 104812 & GYS1 & 38.29 & 130.6 & 0.25 & 1.90 & 3.41 & 7.56 \\
\hline 197901 & OAT1 (SLC22A6) & 0 & 0 & - & - & - & - \\
\hline 137204 & OAT2 (SLC22A7) & 0 & 0 & - & - & - & - \\
\hline 149452 & OAT3 (SLC22A8) & 0 & 0 & - & - & - & - \\
\hline 168065 & OAT4 (SLC22A11) & 0 & 0 & - & - & - & - \\
\hline
\end{tabular}

* Using total RNA-seq gene quantification data in files ENCFF581EE and ENCFF580JSN (LHCN-M2 myoblasts (Day 0) and myotubes (Day 4) respectively) taken from the ENCODE database (66).

${ }^{1}$ Fragments Per Kilobase of transcript per Million mapped reads. 


\section{References}

1. Lauritzen, H. P. M. M., and Schertzer, J. D. (2010) Measuring GLUT4 translocation in mature muscle fibers. American Journal of Physiology - Endocrinology And Metabolism 299, E169-E179

2. Mueckler, M., and Thorens, B. (2013) The SLC2 (GLUT) family of membrane transporters. Molecular aspects of medicine 34, 121-138

3. Cura, A. J., and Carruthers, A. (2012) Role of monosaccharide transport proteins in carbohydrate assimilation, distribution, metabolism, and homeostasis. Comprehensive Physiology 2, 863-914

4. Saltiel, A. R., and Kahn, C. R. (2001) Insulin signalling and the regulation of glucose and lipid metabolism. Nature 414, 799-806

5. Stanford, K. I., and Goodyear, L. J. (2014) Exercise and type 2 diabetes: molecular mechanisms regulating glucose uptake in skeletal muscle. Advances in physiology education 38, 308-314

6. Cheng, C. W., Villani, V., Buono, R., Wei, M., Kumar, S., Yilmaz, O. H., Cohen, P., Sneddon, J. B., Perin, L., and Longo, V. D. (2017) Fasting-Mimicking Diet Promotes Ngn3Driven beta-Cell Regeneration to Reverse Diabetes. Cell 168, 775-788 e712

7. Franco-Obregon, A., and Gilbert, J. A. (2017) The Microbiome-Mitochondrion Connection: Common Ancestries, Common Mechanisms, Common Goals. mSystems 2

8. Steves, C. J., Bird, S., Williams, F. M., and Spector, T. D. (2016) The Microbiome and Musculoskeletal Conditions of Aging: A Review of Evidence for Impact and Potential Therapeutics. J Bone Miner Res 31, 261-269

9. Mach, N., and Fuster-Botella, D. (2017) Endurance exercise and gut microbiota: A review. J Sport Health Sci 6, 179-197

10. Barton, W., Penney, N. C., Cronin, O., Garcia-Perez, I., Molloy, M. G., Holmes, E., Shanahan, F., Cotter, P. D., and O'Sullivan, O. (2017) The microbiome of professional 
athletes differs from that of more sedentary subjects in composition and particularly at the functional metabolic level. Gut

11. Lantier, L., Fentz, J., Mounier, R., Leclerc, J., Treebak, J. T., Pehmoller, C., Sanz, N., Sakakibara, I., Saint-Amand, E., Rimbaud, S., Maire, P., Marette, A., Ventura-Clapier, R., Ferry, A., Wojtaszewski, J. F., Foretz, M., and Viollet, B. (2014) AMPK controls exercise endurance, mitochondrial oxidative capacity, and skeletal muscle integrity. FASEB J 28, $3211-3224$

12. Clark, A., and Mach, N. (2017) The Crosstalk between the Gut Microbiota and Mitochondria during Exercise. Front Physiol 8, 319

13. Louis, P., and Flint, H. J. (2017) Formation of propionate and butyrate by the human colonic microbiota. Environ Microbiol 19, 29-41

14. Stilling, R. M., van de Wouw, M., Clarke, G., Stanton, C., Dinan, T. G., and Cryan, J. F. (2016) The neuropharmacology of butyrate: The bread and butter of the microbiota-gutbrain axis? Neurochem Int 99, 110-132

15. Duncan, S. H., Russell, W. R., Quartieri, A., Rossi, M., Parkhill, J., Walker, A. W., and Flint, H. J. (2016) Wheat bran promotes enrichment within the human colonic microbiota of butyrate-producing bacteria that release ferulic acid. Environ Microbiol 18, 2214-2225

16. Jung, T. H., Jeon, W. M., and Han, K. S. (2015) In Vitro Effects of Dietary Inulin on Human Fecal Microbiota and Butyrate Production. J Microbiol Biotechnol 25, 1555-1558

17. Peyron, S., Abecassis, J., Autran, J. C., and Rouau, X. (2001) Enzymatic oxidative treatments of wheat bran layers: effects on ferulic acid composition and mechanical properties. J Agric Food Chem 49, 4694-4699

18. Del Rio, D., Rodriguez-Mateos, A., Spencer, J. P., Tognolini, M., Borges, G., and Crozier, A. (2013) Dietary (poly)phenolics in human health: structures, bioavailability, and evidence of protective effects against chronic diseases. Antioxidants \& redox signaling 18, $1818-1892$

19. Williamson, G., and Clifford, M. N. (2010) Colonic metabolites of berry polyphenols: the missing link to biological activity? The British journal of nutrition 104 Suppl 3, S48-66 
20. Williamson, G., and Clifford, M. N. (2017) Role of the small intestine, colon and microbiota in determining the metabolic fate of polyphenols. Biochemical pharmacology 139, 24-39

21. Cardona, F., Andres-Lacueva, C., Tulipani, S., Tinahones, F. J., and Queipo-Ortuno, M. I. (2013) Benefits of polyphenols on gut microbiota and implications in human health. The Journal of nutritional biochemistry 24, 1415-1422

22. Williamson, G., Barron, D., Shimoi, K., and Terao, J. (2005) In vitro biological properties of flavonoid conjugates found in vivo. Free radical research 39, 457-469

23. O'Leary, K. A., Day, A. J., Needs, P. W., Mellon, F. A., O'Brien, N. M., and Williamson, G. (2003) Metabolism of quercetin-7- and quercetin-3-glucuronides by an in vitro hepatic model: the role of human beta-glucuronidase, sulfotransferase, catechol-Omethyltransferase and multi-resistant protein 2 (MRP2) in flavonoid metabolism. Biochemical pharmacology 65, 479-491

24. Bareja, A., Holt, J. A., Luo, G., Chang, C., Lin, J., Hinken, A. C., Freudenberg, J. M., Kraus, W. E., Evans, W. J., and Billin, A. N. (2014) Human and mouse skeletal muscle stem cells: convergent and divergent mechanisms of myogenesis. PloS one 9, e90398

25. Gould, G. W., and Holman, G. D. (1993) The glucose transporter family: structure, function and tissue-specific expression. Biochemical Journal 295, 329-341

26. Zhu, C. H., Mouly, V., Cooper, R. N., Mamchaoui, K., Bigot, A., Shay, J. W., Di Santo, J. P., Butler-Browne, G. S., and Wright, W. E. (2007) Cellular senescence in human myoblasts is overcome by human telomerase reverse transcriptase and cyclin-dependent kinase 4: consequences in aging muscle and therapeutic strategies for muscular dystrophies. Aging cell 6, 515-523

27. Fumeaux, R., Menozzi-Smarrito, C., Stalmach, A., Munari, C., Kraehenbuehl, K., Steiling, H., Crozier, A., Williamson, G., and Barron, D. (2010) First synthesis, characterization, and evidence for the presence of hydroxycinnamic acid sulfate and glucuronide conjugates in human biological fluids as a result of coffee consumption. Org. Biomol. Chem 8, 5199-5211 
28. Wong, C. C., Botting, N. P., Orfila, C., Al-Maharik, N., and Williamson, G. (2011) Flavonoid conjugates interact with organic anion transporters (OATs) and attenuate cytotoxicity of adefovir mediated by organic anion transporter 1 (OAT1/SLC22A6). Biochemical pharmacology 81, 942-949

29. Pimpao, R. C., Ventura, M. R., Ferreira, R. B., Williamson, G., and Santos, C. N. (2015) Phenolic sulfates as new and highly abundant metabolites in human plasma after ingestion of a mixed berry fruit puree. The British journal of nutrition 113, 454-463

30. Pimpao, R. C., Dew, T., Figueira, M. E., McDougall, G. J., Stewart, D., Ferreira, R. B., Santos, C. N., and Williamson, G. (2014) Urinary metabolite profiling identifies novel colonic metabolites and conjugates of phenolics in healthy volunteers. Molecular nutrition \& food research 58, 1414-1425

31. Strober, W. (2001) Trypan blue exclusion test of cell viability. Current protocols in immunology Appendix 3, Appendix 3B

32. Smith, P. K., Krohn, R. I., Hermanson, G. T., Mallia, A. K., Gartner, F. H., Provenzano, M. D., Fujimoto, E. K., Goeke, N. M., Olson, B. J., and Klenk, D. C. (1985) Measurement of protein using bicinchoninic acid. Analytical biochemistry 150, 76-85

33. Gardner, S., Anguiano, M., and Rotwein, P. (2012) Defining Akt actions in muscle differentiation. American journal of physiology. Cell physiology 303, C1292-1300

34. Clarke, J. F., Young, P. W., Yonezawa, K., Kasuga, M., and Holman, G. D. (1994) Inhibition of the translocation of GLUT1 and GLUT4 in 3T3-L1 cells by the phosphatidylinositol 3-kinase inhibitor, wortmannin. The Biochemical journal 300 ( Pt 3), 631-635

35. Kohn, A. D., Barthel, A., Kovacina, K. S., Boge, A., Wallach, B., Summers, S. A., Birnbaum, M. J., Scott, P. H., Lawrence, J. C., Jr., and Roth, R. A. (1998) Construction and characterization of a conditionally active version of the serine/threonine kinase Akt. The Journal of biological chemistry 273, 11937-11943

36. Ernst, O., and Zor, T. (2010) Linearization of the bradford protein assay. Journal of visualized experiments : JoVE 
37. Bradford, M. M. (1976) A rapid and sensitive method for the quantitation of microgram quantities of protein utilizing the principle of protein-dye binding. Analytical biochemistry 72, 248-254

38. Wang, H., and Joseph, J. A. (1999) Quantifying cellular oxidative stress by dichlorofluorescein assay using microplate reader. Free radical biology \& medicine 27, 612616

39. Aft, R. L., Zhang, F. W., and Gius, D. (2002) Evaluation of 2-deoxy-D-glucose as a chemotherapeutic agent: mechanism of cell death. British journal of cancer 87, 805-812

40. Goffart, S., Franko, A., Clemen, C. S., and Wiesner, R. J. (2006) Alpha-actinin 4 and BAT1 interaction with the cytochrome c promoter upon skeletal muscle differentiation. Current genetics 49, 125-135

41. Iovino, S., Burkart, A. M., Warren, L., Patti, M. E., and Kahn, C. R. (2016) Myotubes derived from human-induced pluripotent stem cells mirror in vivo insulin resistance. Proceedings of the National Academy of Sciences of the United States of America 113, 18891894

42. Al-Khalili, L., Chibalin, A. V., Kannisto, K., Zhang, B. B., Permert, J., Holman, G. D., Ehrenborg, E., Ding, V. D., Zierath, J. R., and Krook, A. (2003) Insulin action in cultured human skeletal muscle cells during differentiation: assessment of cell surface GLUT4 and GLUT1 content. Cellular and molecular life sciences : CMLS 60, 991-998

43. Stoupi, S., Williamson, G., Drynan, J. W., Barron, D., and Clifford, M. N. (2010) A comparison of the in vitro biotransformation of (-)-epicatechin and procyanidin B2 by human faecal microbiota. Mol. Nutr. Food Res 54, 747-759

44. Stalmach, A., Mullen, W., Barron, D., Uchida, K., Yokota, T., Cavin, C., Steiling, H., Williamson, G., and Crozier, A. (2009) Metabolite profiling of hydroxycinnamate derivatives in plasma and urine after the ingestion of coffee by humans: identification of biomarkers of coffee consumption. Drug metabolism and disposition: the biological fate of chemicals $\mathbf{3 7}$, $1749-1758$ 
45. Guy, P. A., Renouf, M., Barron, D., Cavin, C., Dionisi, F., Kochhar, S., Rezzi, S., Williamson, G., and Steiling, H. (2009) Quantitative analysis of plasma caffeic and ferulic acid equivalents by liquid chromatography tandem mass spectrometry. Journal of chromatography. B, Analytical technologies in the biomedical and life sciences 877, 39653974

46. Fardet, A. (2010) New hypotheses for the health-protective mechanisms of wholegrain cereals: what is beyond fibre? Nutrition research reviews $\mathbf{2 3}, 65-134$

47. Bassham, J. A., Bissell, M. J., and White, R. C. (1974) Quantitative tracer studies of metabolic dynamics of animal cells growing in tissue culture. Anal Biochem 61, 479-491

48. Bhattacharya, S., Christensen, K. B., Olsen, L. C., Christensen, L. P., Grevsen, K., Faergeman, N. J., Kristiansen, K., Young, J. F., and Oksbjerg, N. (2013) Bioactive components from flowers of Sambucus nigra L. increase glucose uptake in primary porcine myotube cultures and reduce fat accumulation in Caenorhabditis elegans. Journal of agricultural and food chemistry 61, 11033-11040

49. Ho, G. T., Kase, E. T., Wangensteen, H., and Barsett, H. (2017) Phenolic Elderberry Extracts, Anthocyanins, Procyanidins, and Metabolites Influence Glucose and Fatty Acid Uptake in Human Skeletal Muscle Cells. Journal of agricultural and food chemistry $\mathbf{6 5}$, 2677-2685

50. Prabhakar, P. K., and Doble, M. (2009) Synergistic effect of phytochemicals in combination with hypoglycemic drugs on glucose uptake in myotubes. Phytomedicine : international journal of phytotherapy and phytopharmacology 16, 1119-1126

51. Kawabata, K., Sawada, K., Ikeda, K., Fukuda, I., Kawasaki, K., Yamamoto, N., and Ashida, H. (2011) Prenylated chalcones 4-hydroxyderricin and xanthoangelol stimulate glucose uptake in skeletal muscle cells by inducing GLUT4 translocation. Molecular nutrition \& food research 55, 467-475

52. Eid, H. M., Martineau, L. C., Saleem, A., Muhammad, A., Vallerand, D., BenhaddouAndaloussi, A., Nistor, L., Afshar, A., Arnason, J. T., and Haddad, P. S. (2010) Stimulation of AMP-activated protein kinase and enhancement of basal glucose uptake in muscle cells by 
quercetin and quercetin glycosides, active principles of the antidiabetic medicinal plant Vaccinium vitis-idaea. Mol Nutr Food Res 54, 991-1003

53. Eid, H. M., Nachar, A., Thong, F., Sweeney, G., and Haddad, P. S. (2015) The molecular basis of the antidiabetic action of quercetin in cultured skeletal muscle cells and hepatocytes. Pharmacognosy magazine 11, 74-81

54. Manach, C., Morand, C., Crespy, V., Demigne, C., Texier, O., Regerat, F., and Remesy, C. (1998) Quercetin is recovered in human plasma as conjugated derivatives which retain antioxidant properties. FEBS Lett 426, 331-336

55. Breen, D. M., Sanli, T., Giacca, A., and Tsiani, E. (2008) Stimulation of muscle cell glucose uptake by resveratrol through sirtuins and AMPK. Biochemical and biophysical research communications $\mathbf{3 7 4 , 1 1 7 - 1 2 2}$

56. Park, C. E., Kim, M. J., Lee, J. H., Min, B. I., Bae, H., Choe, W., Kim, S. S., and Ha, J. (2007) Resveratrol stimulates glucose transport in C2C12 myotubes by activating AMPactivated protein kinase. Experimental \& molecular medicine 39, 222-229

57. de Ferrars, R. M., Czank, C., Zhang, Q., Botting, N. P., Kroon, P. A., Cassidy, A., and Kay, C. D. (2014) The pharmacokinetics of anthocyanins and their metabolites in humans. British Journal of Pharmacology 171, 3268-3282

58. Czank, C., Cassidy, A., Zhang, Q., Morrison, D. J., Preston, T., Kroon, P. A., Botting, N. P., and Kay, C. D. (2013) Human metabolism and elimination of the anthocyanin, cyanidin-3-glucoside: a (13)C-tracer study. The American journal of clinical nutrition 97, 995-1003

59. Scazzocchio, B., Vari, R., Filesi, C., Del Gaudio, I., D'Archivio, M., Santangelo, C., Iacovelli, A., Galvano, F., Pluchinotta, F. R., Giovannini, C., and Masella, R. (2015) Protocatechuic acid activates key components of insulin signaling pathway mimicking insulin activity. Molecular nutrition \& food research 59, 1472-1481

60. Yamamoto, N., Ueda, M., Kawabata, K., Sato, T., Kawasaki, K., Hashimoto, T., and Ashida, H. (2010) Artemisia princeps extract promoted glucose uptake in cultured L6 muscle 
cells via glucose transporter 4 translocation. Bioscience, biotechnology, and biochemistry $\mathbf{7 4}$, 2036-2042

61. Agronomique., I. N. d. 1. R. (2014) PhytoHub version 1.0: a food metabolome database dedicated to dietary phytochemicals.

62. Wong, C. C., Akiyama, Y., Abe, T., Lippiat, J. D., Orfila, C., and Williamson, G. (2012) Carrier-mediated transport of quercetin conjugates: involvement of organic anion transporters and organic anion transporting polypeptides. Biochemical pharmacology $\mathbf{8 4}$, $564-570$

63. Stalmach, A., Steiling, H., Williamson, G., and Crozier, A. (2010) Bioavailability of chlorogenic acids following acute ingestion of coffee by humans with an ileostomy. Archives of biochemistry and biophysics 501, 98-105

64. Stull, A. J., Cash, K. C., Johnson, W. D., Champagne, C. M., and Cefalu, W. T. (2010) Bioactives in blueberries improve insulin sensitivity in obese, insulin-resistant men and women. The Journal of nutrition 140, 1764-1768

65. Torronen, R., Kolehmainen, M., Sarkkinen, E., Poutanen, K., Mykkanen, H., and Niskanen, L. (2013) Berries reduce postprandial insulin responses to wheat and rye breads in healthy women. The Journal of nutrition 143, 430-436

66. (2012) An integrated encyclopedia of DNA elements in the human genome. Nature 489, $57-74$ 